\title{
Article \\ Optimizing Design of Smart Workplace through Multi-Objective Programming
}

\author{
Shady Aly ${ }^{1, *}$, Jan Tyrychtr ${ }^{2}$ and Ivan Vrana ${ }^{2}$ (]) \\ 1 Department of Mechanical Engineering, Faculty of Engineering at Helwan, Helwan University, \\ Cairo 11792, Egypt \\ 2 Department of Information Engineering, Faculty of Economics \& Management, \\ Czech University of Life Sciences, 16500 Praha-Suchdol, Czech Republic; tyrychtr@pef.czu.cz (J.T.); \\ vrana@pef.czu.cz (I.V.) \\ * Correspondence: shady_ali@h-eng.helwan.edu.eg
}

Citation: Aly, S.; Tyrychtr, J.; Vrana, I. Optimizing Design of Smart Workplace through Multi-Objective Programming. Appl. Sci. 2021, 11, 3042. https://doi.org/10.3390/ app11073042

Academic Editor: Ludmila Dymova

Received: 24 February 2021

Accepted: 21 March 2021

Published: 29 March 2021

Publisher's Note: MDPI stays neutral with regard to jurisdictional claims in published maps and institutional affiliations.

Copyright: (c) 2021 by the authors. Licensee MDPI, Basel, Switzerland. This article is an open access article distributed under the terms and conditions of the Creative Commons Attribution (CC BY) license (https:// creativecommons.org/licenses/by/ $4.0 /)$.

\begin{abstract}
Smart environments have proven very supportive to the improvement of the performance of people in different workplaces. Plenty of applications have been introduced spanning different settings including healthcare, ambient assisted living, homes, offices, and manufacturing environment, etc. However, subjectivity and ambiguity prevail in the majority of research, and still, up to date, rare approaches found quantitatively and objectively constructing or assessing the impact of smart enabling technologies on the performance of the subject environment. Further, no approaches have considered optimizing the adoption of those smart technologies with respect to objectives achievement. This article presents a novel optimization methodology for designing a smart workplace environment in conditions of ambiguity or fuzziness. The methodology begins with defining and weighing the overall goals and objectives of the workplace. The Prometthe multi-criterion decisionmaking technique is used to weigh the operational objectives with respect to the overall workplace goals. Next, the relation among basic building blocks of the model; namely: the operational objectives, smartness features, and smart enabling technologies are quantified, utilizing fuzzy relations. Then, the fuzzy goal programming techniques will be utilized to optimize the impact relation values while considering the budget constraint. The proposed optimization methodology is implemented on the development and optimization of the smart clinic, as a typical instance of the workplace.
\end{abstract}

Keywords: smart environment (SE); smart enabling technologies (SETs); PROMETTHEE; fuzzy logic (FL); fuzzy relations (FR); fuzzy goal programming (FGP); mixed-integer programming (MIP)

\section{Introduction}

Smart enabling technologies represent the major fundamental building blocks of the smart environment application. Due to the need to justify their application and in circumstances of limited financial resources, it is highly demanded to optimize their exploitation in developing smart environment applications for various types and environmental settings. Currently, the decision of applying smart enabling technologies to develop a smart environment development is carried out with improvisation and based only on estimation, the intuition of the system analysts or involved practitioners. This unfortunately can involve great risk if the smart enabling technologies adoption decision has not been studied, analyzed carefully, and optimized for sake of economic efficiency. Hospitals, clinics, and healthcare are currently very attractive applications of smart enabling technologies (SETs), particularly in the times of the Covid19 pandemic. Hospitals are seeking solutions to improve their productivity, safety, staff satisfaction, and efficiency, to reduce costs and improve margins, and to cope with the heavy service loads. Hospitals around the world are under huge pressure today and deal with factors such as cost and crowd pressures while, at the same time, have to provide health care in a smart and efficient way to an increasing number of patients. The exploitation of the SETs can play a positive role in 
improving operational performance and can reflect as well positively in reducing the risk of infections that can be incurred as a cause of any malfunctions and deficiencies in the operational practices. In fact, the implementation of SETs in hospitals can lead to the optimization of several services and activities. The literature on smart workplace environment development is very progressive and highly influenced by the continual emergence of new SETs. Several research attempts have addressed the development of a smart workplace. Kbar and Aly (2014) [1] proposed a scenario for utilizing the ambient intelligence and ICT technologies (e.g., Speech and Voice over IP to develop a smart workplace environment aiming to enhance the inclusion of persons with disabilities in the workplace environment and support them in doing their work tasks. Kbar et al. (2015) [2] introduced smart help solution for physically disabled persons (PDP) to support access of PDP to relevant information and communicate with others effectively through smart editors utilizing speech recognition engine and Voice over IP (VoIP). Aly et al. (2017) [3] introduced a methodology for designing a smart manufacturing environment utilizing a fuzzy screening approach. The fuzzy screening approach is used to assess the merits of the SETs with respect to the objectives and opportunities to enhance the performance of manufacturing workplace tasks and the elicited logical improvement opportunities. Aly et al. (2018) [4] presented a novel methodology to design a smart workplace environment to achieve objectives and improve performance. Fuzzy relations were utilized to model and quantify vague influence relations among related goals, objectives, concepts, and smart technologies. Tian et al. (2019) [5] listed the key supporting technologies of smart healthcare and reviewed its current status. They pinpointed the current problems with smart healthcare and suggested solutions to solve them. Turk et al. (2020) [6] presents a smart assembly system controlled by a smart algorithm through digital human modeling for the personalization of assembly workstations. Turk et al. (2021) [7] studied the impact of SETs on the performance of a new manual assembly station. They demonstrated the effectiveness of the implemented technologies through a case study, which includes a comparison of assembly times and the number of errors before and after implementation. Forcina et al. (2021) [8] conducted a literature review to investigate how maintenance function is influenced by Industry $4.0^{\prime} \mathrm{s}$ technologies. Their analysis aimed to identify the most suited technology employed in maintenance tasks. Zhao et al. (2021) [9] implemented a network of physical sensors and a closed control loop to optimize an office workplace environment. They applied two modes of control involving learning from user responses and the other was based on predefined rules sets. Tewary et al. (2016) [10] designed a smart health monitoring system to automate patient monitoring tasks. They developed a GSM (Global System for Mobile) based smart wearable system with 3-axis Accelerometer, ECG recording system, and real-time NIBP analysis system. Khan and Chattopadhyay (2017) [11] presented a smart health monitoring system that uses biomedical sensors to check a patient's condition and report it through the internet to inform the concerned doctors either through an LCD monitor or through a developed smartphone mobile application. Khayal and Farid (2017) [12] architected a Cyber-Physical system model for personalized healthcare delivery and managed individual health outcomes. Arefin et al. (2017) [13] proposed a wireless network infrastructure that provides health and medical services to children and adults as well as assists in distributing tablets, vaccines to monitor endemic diseases. Bansal and Gandhi (2019)[14] emphasized the role of utilizing IoT together with Big Data technologies in transmitting ECG sensors data from the patient to the doctors and other concerned persons for effective and efficient smart health monitoring. They stated that IoT helps the ECG signals to get transmitted through the sensor via a gateway using communication protocols like Bluetooth, Zigbee, 3G/4G, Wi-Fi, LAN, etc. Feng et al. (2019) [15] investigated the mobile phone software or hospital official network of smart healthcare in the current Chinese market environment and analyzed the main functions and shortcomings with the aboriginal lens. Almazroa et al. (2019) [16], proposed a smart sensing mobile application that can collect data coming from the body temperature sensor through the network, then processes it based on some analysis to provide the mobile 
user the needed information and the decision to take in case of an emergency situation. Kamruzzaman (2020) [17] proposed the architecture of a smart healthcare system using artificial intelligence as a tool for optimizing patient care plans. He pointed out that the proposed system enables the early detection of serious diseases and can automatically recognize the complicated patterns and produces AI-generated radiologist and clinical reports. Rajakumari et al. (2020) [18] presented a convolution neural network-based smart hospital and patient scheduling system, to assist patients comfortably while planning to visit the clinic and without any heavy burden to consult a doctor for their needs. Xie et al. (2020) [19] proposed a design of a hospital IoT smart system and nucleoside drugs for the treatment of hepatitis and liver cirrhosis. Zhao et al. (2020) [20] presented a smart IoT platform in the hospital that can relieve postoperative pain. Ahmid et al. (2020) [21] proposed an intelligent health monitoring system based on based on IoT and agents that monitor the patients' heart rate automatically and can anticipate the critical condition before happening and send an alerting message to the patient family, doctors, nurses, as well as hospital in-charge.

Indeed, the literature reveals that currently there is no objective model or techniques used to guide the systematic development optimization of smart environment development decisions. Rather, the majority of the proposed contributions present a scenario or subjective description of the implementation of some partial subsets of the enabling technologies (i.e., SETs), without stating a systematic procedure for structuring a method for how to adopt SETs, including specifying the model relationships among environment's objectives, smart features and enabling technologies, and how objectives or quantitatively optimize these features and technologies to best contribute to the realization of objectives. In this article, we present a systematic methodology for not only guiding the adoption of the SETs, but also for optimizing their impact on the defined objectives and overall goals of the workplace, and through quantifying the ambiguous relations among the workplace operational objectives, smartness features, and the SETs. This is through applying fuzzy relations and fuzzy goal programming. We illustrate the methodology on a smart clinic case example.

The article is organized as follows. Section two reviews the state-of-the-art SETs. In section three, the basic building blocks of the smart workplace proposed model are introduced. Section four presents the proposed methodology for optimizing the design of a workplace utilizing three techniques: the multi-criterion decision-making tool, PROMETHEE, fuzzy relations, and fuzzy goal programming. An illustrative case example is provided for optimizing the design of a smart clinic workplace. In section six, a conclusion is made.

\section{Smart Environment and Technologies}

In this section, we present the result of the conducted survey of the state-of-the-art and common smart technologies and features. However, before, it is important first to define what is meant by a smart environment, and what its basic constituents are. A typical smart environment would consist of the following basic building blocks or elements [22,23]:

Environment objects: Appliances, furniture, equipment, devices, and any other resources that provide essential necessities or needs for the occupants or users. Smart environment objects are those equipped with sensors, actuators, and communication capabilities.

Sensors: monitors activities, behavior status of users or resources, and send messages to a control system.

Actuators: receive control signals to perform real-time physical action.

Interfaces: enable user's communication with the system.

Control systems: apply a set of programmed rules, using the information sent by sensors and through instructions sent to actuators to achieve high-level goals of the environment. Networks: allows communication between the control system, sensors, actuators, smart environment objects. This includes wireless networks: LAN, WiFi, Bluetooth, etc.

Middleware: The integration and interoperability of heterogeneous devices are achieved by an intermediary software layer called middleware. 
Actually, currently there exist so many options and brands for various sensing technologies, like motion, position, physiological and biomedical, and various physical measurement sensors (e.g., positioning sensors: RFID [24], motion sensors [22,24], pressure sensor [23], physiological sensors: Electrocardiography (ECG) [24,25] and EMG (Electromyography) $[24,26]$, etc.). Additionally, other sophisticated smart systems include Smartwatch [27], Eye tracker [28], Computer brain interface (CBI) [29]). However, even though the rapid and continual emergence of SETs and availability of so many alternatives for each technology type, actually this makes the problem of assessing and justifying investment in these technologies more and more difficult. Currently, there are no structured, objective, and systematic means for differentiating among these wide spectra of available SETs, nor exist an approach that considers the costs of the technologies and the available budget for the project of developing smart hospitals.

The table in Appendix A, shows a set of relevant smart enabling technologies (SETs), studied based on the current literature. The table lists what they measure, their potential application in hospitals or healthcare facilities, and their estimated cost ranges. In this article, we will not have an interest in our investigation on a specific trademark, brand, or developing firm of smart environment technologies, but rather we will focus on the capability and functionality.

Next section, we present the proposed methodology for optimizing the design of the smart workplace.

\section{Smart Workplaces: Model Building Blocks}

The smart workplace environment is logically built around three basic model building blocks:

The smart enabling technologies (SETs): sensors, actuators, microcontrollers, and other basic software and hardware constituents that shall be installed in the workplace environment, such as offices, industrial plants, hospitals, etc. These technologies percept, reason, and acts in the hospital environment for realizing some smart features or aspects (See Table A1 in the Appendix A for the survey of the state of the art).

The smartness features (SFs): the intelligent or smart characteristics, aspects, or attributes that are commonly adopted for smart workplace environments, such as assets tracking, context awareness, indoor/outdoor positioning, etc. These smartness features are to be implemented or introduced in the subject workplace environment by installing the SETs.

The operational objectives (OOs): the workplace operations' level objectives or aims of the workplace various activities and operations such as optimizing the flow of people, optimizing the flow of objects, minimizing handling costs, and materials and other objects, management operations and activities that are significant to achieve.

Next section, we present the smart workplace design methodology.

\section{Proposed Smart Workplace Design Optimization Procedure}

In this section, we introduce the proposed smart workplace design optimization procedure (See Figure 1). The proposed procedure starts with analyzing the workplace environment to define the basic model building blocks elements. In step 2, the workplace goals, operational objectives are accurately detailed and specified. Next, it will be significant to rank and weigh the importance of each goal, objectives in their hierarchy. This is achieved in step 3. After, in step 4, we list the commonly available smart enabling technologies (SETs), and their average cost estimates based on a literature survey and commercial reports. Then, in step 5, based on their nature of the workplace, we survey the relevant and widely addressed and implemented smartness attributes or features, which are related to the implementation of SETs. Step 6 involves constructing fuzzy positive impact relations among defined model building blocks in step 1 and whose elements were detailed in steps 2 through 5 . Expert decision analysts assign their judgments to quantify relations among model elements using linguistic or direct numeric values utilizing an established psycho- 
metric scale. In step 7, we employ the fuzzy relations' composition operator to combine the linked direct fuzzy relations to attain the target indirect positive impact relations between the SETs and the operational objectives of the workplace to enable making preference judgment and optimization of SETs impacts. Step 8 involves developing a conceived logical scenario for deploying the different types of SETs in the workplace environment. This is important to estimate the number of individual SET and their corresponding costs. Step 9 collects several outputs of steps 3,7 , and 8 , including the weights of each operational objective, positive impact relations values of each of the SETs on each of the operational objectives, and the cost estimate of SETs computed as the multiplication of their quantities by the unit costs. Then, we formulate multiple objective fuzzy goal programming models to optimize the adoption of SETs in the smart workplace design, based on maximizing their total positive impact values on each operational objective, while satisfying the total budget limit constraint. Step 10 should be conducted as a post-implementation stage, through assessing the actual performance of the deployed SETs. In fact, the scope of this research focuses on the optimization stage.

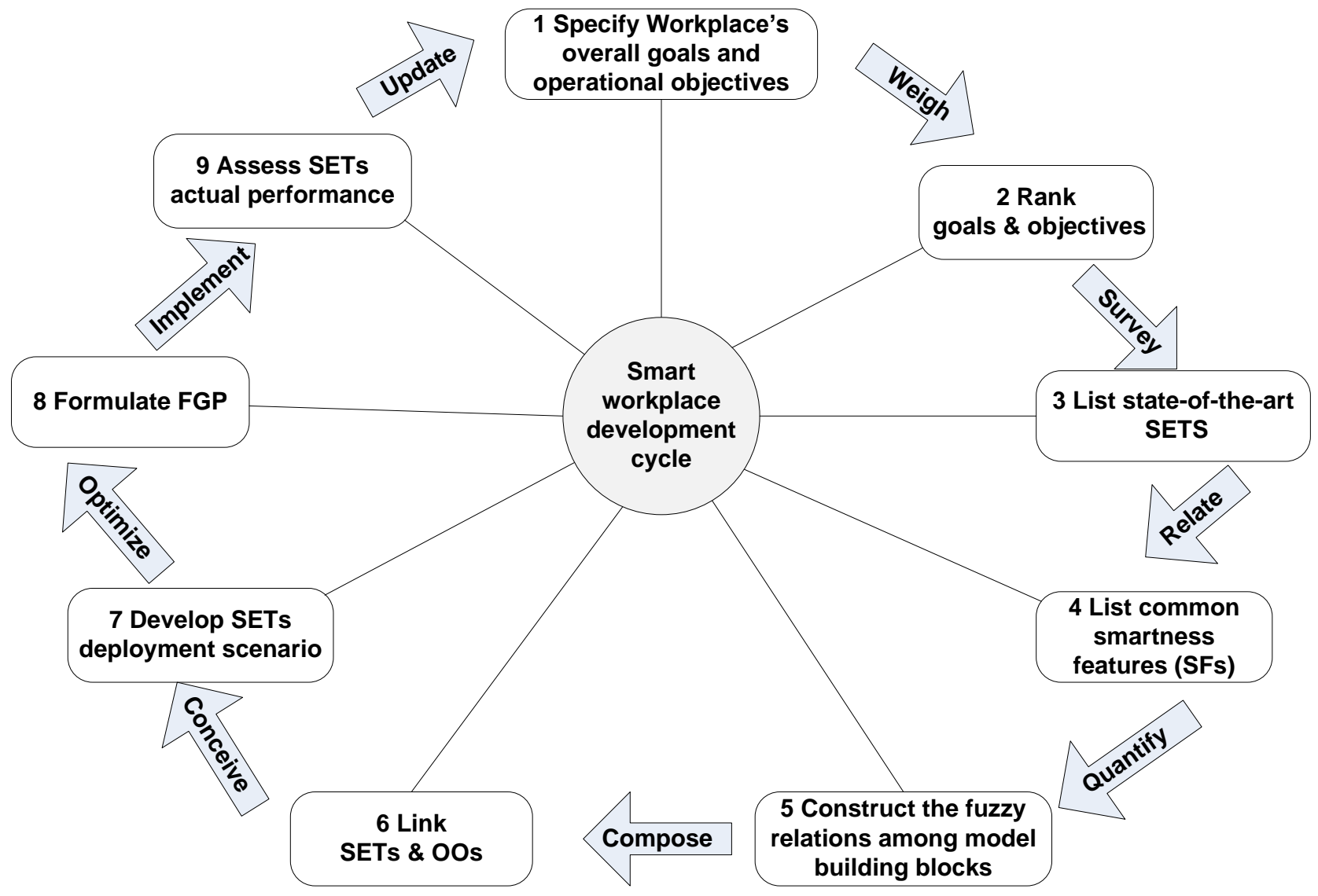

Figure 1. Smart workplace design procedure.

We shall present an illustrative case example of optimizing the design of a smart clinic environment. Figure 2 depicts the conceptual relations among the smart workplace model building blocks, which clarify the decision-making hierarchy provided in this model. At the top of the model hierarchy is the workplace overall goals. Then, down in the hierarchy are the operational level objectives (i.e., the task, operation, or activity level). Each of these operational objectives has significance to the realization of each of the overall goals, expressed by the weights as shown. The operational objectives (OOs) represent the first model building blocks, which have the first fuzzy relations to the smartness features, that are quantified by the expert decision analyst. In their turn, the smartness features (SFs) have the second fuzzy relation to the smart enabling technologies (SETs). These two direct 
fuzzy relations are combined by a fuzzy relations composition operator to determine the target indirect fuzzy relation between the OOs and the SETs. The fuzzy goal programming optimization model utilizes the positive impact values in such fuzzy relation to maximizing the overall positive impact of SETs to attain the optimal subset of SETs, SETs*, while not exceeding the project development budget limit constraint. In fact, the three model building blocks: OOs, SFs, and SETs are the cornerstones needed to understand the impact of SETs on OOs, and the basis for evaluating them. On the other hand, weights, fuzzy relations, and fuzzy goal programming are the means used to quantifying, evaluating and optimizing these impacts.

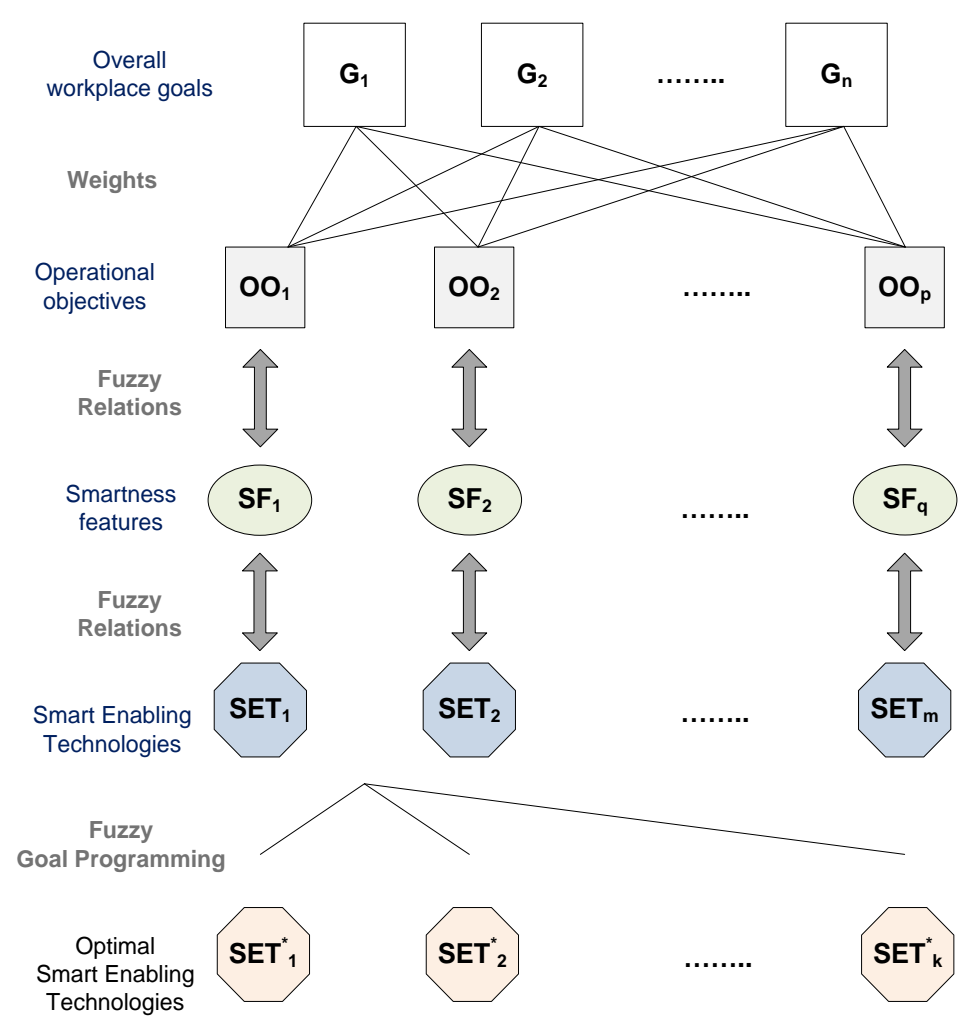

Figure 2. Smart workplace model building blocks.

Next section, we present the PROMETHEE technique that will be utilized to weigh the operational objectives of the workplace.

\subsection{PROMETHEE}

PROMETHEE [30-33] stands for the Preference Ranking Organization Method for Enrichment of Evaluations. It is a multi-criterion decision aiding tool that utilizes pair-wise comparison of alternatives for each criterion to determine the strength of preference of alternative $a$ over alternative $b$. The implementation of PROMETHEE evaluation involves mainly quantitative data and it requires additional information, namely:

- $\quad$ The weights of the evaluation criteria considered and

- The decision maker's preference function, used when comparing the performance of the alternatives with respect to each individual criterion.

One distinction process of PROMETHEE is the use of the preference function $\left(P_{j}\right)$ to translate the difference between the evaluations of two alternatives ( $a$ and $b$ ) for a particular criterion, into a preference degree ranging from 0 to 1 . Let $\mathrm{A}$ be a finite set of alternatives, $\mathrm{A}=\left\{a_{1}, a_{2}, \ldots \ldots, a_{n}\right\}, \mathrm{C}$ is a finite set of criteria, $\mathrm{C}=\left\{c_{1}, c_{2}, . ., c_{j} \ldots, c_{k}\right\}$, having a corresponding set of prespecified weights or importance's, $\mathrm{W}=\left\{w_{1}, w_{2}, . ., w_{j} \ldots, w_{k}\right\}$. Then, for two alternatives $a, b \in A$ :

$$
P_{j}(a, b)=G_{j}\left[c_{j}(a)-c_{j}(b)\right]
$$




$$
0 \leq P_{j}(a, b) \leq 1
$$

$P_{j}(a, b)$ is the preference function associated with the criterion performance $c_{j}(i)$ for the $i^{\text {th }}$ alternative, where $G_{j}$ is a non-decreasing function of the observed deviation $d$, between $c_{j}(a)$ and $c_{j}(b)$. The values of the criterion performance, $c_{j}(i)$ of the alternative $i$ can take crisp numerical, linguistic with corresponding numerical scale or fuzzy numbers as in Mergias et al. (2007) [33].

In order to facilitate the selection of a specific preference function, six basic types have been proposed: usual function, U-shape function, V-shape function, level function, linear function and Gaussian function (as presented in Table 1) Brans (1982) [30], Brans and Vincke (1985) [32], Brans and Mareschal (1994) [33].

Table 1. Preference functions of the PROMETHEE technique.

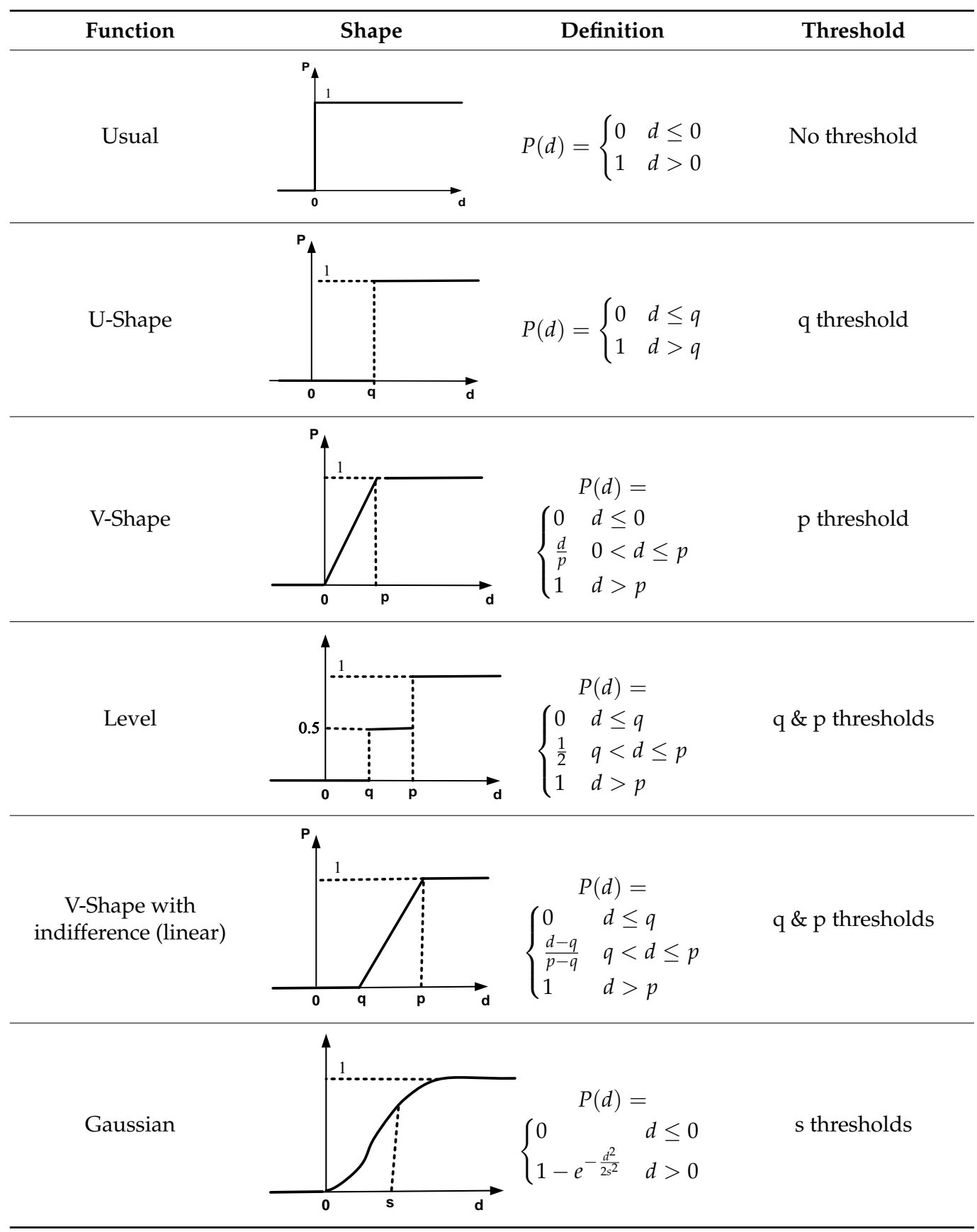


The values of the PROMETHEE compute the following quantities in the pair-wise evaluation of alternatives $a$ and $b$, as follows:

The overall preference index of alternative a over $b,(a, b \in A)$ :

$$
\pi(a, b)=\sum_{j=1}^{k} P_{j}(a, b) w_{j}
$$

The average positive-outranking flow of alternative a:

$$
\varphi_{a}^{+}=\sum_{x \in A} \pi(a, x)
$$

The average negative-outranking flow of alternative a:

$$
\varphi_{a}^{-}=\sum_{x \in A} \pi(x, a)
$$

The net outranking flow of alternative a:

$$
\varphi_{a}^{n e t}=\varphi_{a}^{+}-\varphi_{a}^{-}
$$

where $\varphi_{a}^{\text {net }}$ is called a net flow, and a higher value of it means a higher attractiveness of alternative a.

In this research, we are going to employ the PROMETHEE technique in computing priorities of the workplace's operational objectives, with respect to two prespecified overall goals of the workplace. Detailed results of PROMETHEE computations will be illustrated in the provided example, in Section 5. The computation results are found in Appendix B (Tables A2-A4)

Next section, we present a method for handling vague relations among the smart workplace optimization model building blocks.

\subsection{Fuzzy Relations}

Fuzzy relations have been applied in many areas, such as in fuzzy control, project evaluation, clustering, and inexact modeling. They generalize the concept of relations in the same way the fuzzy sets generalize the concept of sets. The concept of fuzzy set theory was introduced in 1965 by Zadeh [34]. The theory was a means of representing and manipulating data that are not exact or precise, but rather ambiguous or fuzzy. In fuzzy set theory, an element $x$ may partially belong to a set $\mathrm{A}$, expressed by a degree of membership $\mu_{A}(x)$. A fuzzy set $\mathrm{A}$ in $\mathrm{X}$, where $\mathrm{X}$ is a non-empty set, is characterized by its membership function degree:

$$
\mu_{A}: X \rightarrow[0,1]
$$

$\mu_{A}(x)$ is the membership degree of the element $\mathrm{x}$ in the fuzzy set $\mathrm{A}$ for each $\mathrm{x} \in \mathrm{X}$. Where, the value zero represents complete non-membership, the value one represents complete membership and any other values in between are used to represent the intermediate degree of membership. Now, a relation mathematically describes a situation where certain elements of sets are linked to one another in some defined aspect. It is important to distinguish between crisp and fuzzy relations:

\section{- Crisp Relation:}

A crisp relation is defined on the Cartesian product of two universal sets. Let $X, Y \subseteq R$ be two universal sets then, the crisp relation $R$ is defined by its membership function as follows:

$$
\begin{gathered}
R=X \times Y=\{(x, y) \mid x \in X, y \in Y\} \\
\mu_{R}(x, y)=\left\{\begin{array}{l}
1,(x, y) \in R \\
0,(x, y) \notin R
\end{array}\right.
\end{gathered}
$$


where, the value 1 means complete membership for the pair in relation and value 0 means no relation at all.

- Fuzzy relation:

A fuzzy relation is defined also on the Cartesian product of two universal sets. Let, $X$, $Y \subseteq R$ be universal sets, then;

$$
\begin{gathered}
R=X \times Y=\left\{(x, y), \mu_{R}(x, y) \mid x \in X, y \in Y\right\} \\
R: X \times Y \rightarrow[0,1]
\end{gathered}
$$

$R$ is called a fuzzy relation in $X \times Y \subseteq R$. The value 1 means complete membership of pair $(x, y)$ in relation $R$, whereas, the value 0 means complete non-membership, and any value in between means the intermediate degree of membership in $R$. A fuzzy relation $R$ between vectors $x_{m}$ and $y_{n}$ can be presented in the form of a two-dimensional $m \times n$ matrix:

$$
R=\begin{gathered}
x_{1} \\
x_{2} \\
\ldots \\
x_{m}
\end{gathered}\left[\begin{array}{cccc}
\mu_{R}\left(x_{1}, y_{1}\right) & \ldots & \ldots & \mu_{R}\left(x_{1}, y_{n}\right) \\
\ldots & \ldots & \ldots & \ldots \\
\ldots & \ldots & \ldots & \ldots \\
\mu_{R}\left(x_{m}, y_{1}\right) & \ldots & \ldots & \mu_{R}\left(x_{m}, y_{n}\right)
\end{array}\right]
$$

where $\mu_{R}\left(x_{i}, y_{j}\right)$ are membership functions for pair $\left(x_{i}, y_{j}\right)$ in the relation $R$. Fuzzy relation between elements of two sets can be expressed also by linguistic terms, for instance: " $x$ is considerable smaller than $y$ ", " $x$ is very close to $y$ ", and "Approximately equal", etc. In this research, the fuzzy relation "Positively impact" will be established among the three basic model building blocks: SETs, SFs, and OOs of the considered workplace. The construction of fuzzy relation matrices that quantify relations among the mentioned three sets of the model building blocks. This requires a unified numerical scale to quantify the relations using the expert's assigned linguistic value with a corresponding numerical value representing a membership for each element or relation pair. Therefore, to simplify the impact assessment process, a set of experts or specializing decision analysts can assign a linguistic term with a corresponding membership for each relation pair (see Table 2).

Table 2. Fuzzy relations linguistic and numerical membership values scale.

\begin{tabular}{ccc}
\hline $\begin{array}{c}\text { Linguistic Values of Fuzzy } \\
\text { Relation "Positively Impact" (PI) }\end{array}$ & Abbreviation & Membership Value $(\mu)$ \\
\hline "Never" & $\mathrm{N}$ & $0 \leq \mu \leq 0.1$ \\
\hline "Very Slightly" & $\mathrm{V}$ & $0.1<\mu \leq 0.2$ \\
\hline "Slightly" & $\mathrm{S}$ & $0.2<\mu \leq 0.4$ \\
\hline "Moderately" & $\mathrm{M}$ & $0.4<\mu \leq 0.6$ \\
\hline "Highly" & $\mathrm{H}$ & $0.6<\mu \leq 0.8$ \\
\hline "Extremely" & $\mathrm{E}$ & $0.8<\mu \leq 1$ \\
\hline
\end{tabular}

The membership values of the fuzzy relation "Positively impact" are graded from 0 up to one. Negative and neutral impacts are considered as zero up to 0.1 and expressed linguistically as "Never". Using the above linguistic scale, the decision analyst can quantify the relation membership value between every two elements of any two related sets.

In fact, we are mainly interested in obtaining the positive impact relations for the smart enabling technologies on the operational objectives. We can get this relation through the composition of the two relations: the first relation between the SETs and SFs, and the second relation between SFs and OOs. This is done by employing the common fuzzy relations max-min composition operator [34,35], which will be described hereinafter. This aims eventually to be able to quantify the positive impact of various SETs on the operational 
objectives of the smart workplace. The max-min composition operator is formally defined as follows:

Let $X, Y, Z$ be universal sets and let $R$ and $Q$ be relations that relate elements from $X$ to $Y$ and from $Y$ to $Z$, respectively, i.e.,

$$
\begin{aligned}
& R=\left\{\left((x, y), \mu_{R}(x, y)\right)\right\} x \in X, y \in Y, R \subset X \times Y \\
& Q=\left\{\left((y, z), \mu_{Q}(y, z)\right)\right\} y \in Y, z \in Z, Q \subset Y \times Z
\end{aligned}
$$

Then, $S$ will be a relation that relates elements in $X$ that $R$ contains to the elements in $Z$ that $Q$ contains, i.e.,

$$
S=R^{\circ} Q=\left\{\left((x, z), \mu_{S}(x, z)\right)\right\}, x \in X, z \in Z, S \subset X \times Z
$$

Max-Min composition is then defined as

$$
\mu_{s}(x, z)=\max _{y \in Y}\left(\min \left(\mu_{R}(x, y), \mu_{Q}(y, z)\right)\right)
$$

The Max-Min composition is similar to the multiplication of matrices, but instead of multiplication and then addition, we apply the Min then Max operators. As an example: Let $R$ and $Q$ be as follows:

$$
R=\left[\begin{array}{cc}
0.4 & 0.6 \\
0 & 1
\end{array}\right], Q=\left[\begin{array}{ccc}
0.5 & 0.25 & 0.4 \\
0.7 & 1 & 0.8
\end{array}\right] \text {, then } S=R^{\circ} Q=\left[\begin{array}{ccc}
0.6 & 0.6 & 0.6 \\
0.7 & 1 & 0.8
\end{array}\right]
$$

Next section, we review the basic elements of the fuzzy goal programming model, which will be utilized to optimize the positive impact relations values of the SETs on the OOs.

\subsection{Fuzzy Goal Programming}

Traditional goal programming (GP) is a branch of multi-objective optimization. It is an extension of linear programming to manipulate multiple, usually conflicting objective measures. Each of these measures is given a goal or target value required to be achieved. Deviations both above and below from these goals are measured. undesired deviations from this set of target values are then minimized in an objective function called the achievement function.

In GP [36], the simple additive model for m goals, $G_{i}(x)(i=1,2 . ., m)$ with deviational variables $p_{i}, n_{i}$ is defined as:

$$
\sum_{i=1}^{m}\left(p_{i}+n_{i}\right)
$$

Subject to

$$
\begin{aligned}
& G_{i}(x)+n_{i}-p_{i}=g_{i} \\
& n_{i} \bullet p_{i}=0, \\
& n_{i}, p_{i}, g_{j} \geq 0, I=1,2 \ldots, m
\end{aligned}
$$

where: $g_{i}$, represents the aspiration level of the $i$-th goal.

However, in ambiguous decision-making situations, goal levels can be difficult to be specified precisely using exact values. In these situations of ill-defined multi-objective optimization, the fuzzy goal programming (FGP) [37] fits well. In FGP, we use a membership function instead of deviational variables to model deviations from the average levels desired to be achieved. The FGP problem is formulated as:

Find $X$ to satisfy:

$$
G_{i} x \widetilde{>} g_{i}, i=1,2 \ldots, \mathrm{m}
$$

Subject to

$$
A X \leq b
$$


$X \geq 0$

where: $X$ is an $n$-vector with components $x_{1}, x_{2}, \ldots x_{n}$. and $A X \leq b$, are system constraints in vector notation. The symbol ' $>$ ' refers to the fuzzification of the aspiration level (i.e., approximately greater than or equal to). The $i$-th fuzzy goal $G_{i}(x) \widetilde{>} g_{i}$ indicates that the decision-maker is satisfied even if less than $g_{i}$ is achieved up to a specific tolerance limit. To solve the FGP problem, we use a linear membership function for the $i$-th fuzzy goal, $\mu_{i}$ (see Zimmermann (1976), (1978) [35,38]), which can be expressed as follows:

$$
\mu_{i}=\left\{\begin{array}{c}
1 \text { if } G_{i}(x) \geq g_{i} \\
\frac{G_{i}(x)-L_{i}}{g_{i}-L_{i}} \text { if } L_{i} \leq G_{i}(x) \leq g_{i} \\
0 \text { if } G_{i}(x) \leq L_{i}
\end{array}\right.
$$

where: $L_{i}$ is the lower tolerance limit for the fuzzy goal.

In the case of the goal $G_{i}(x) \widetilde{<} g_{i}$, the membership function is defined as:

$$
\mu_{i}=\left\{\begin{array}{c}
1 \text { if } G_{i}(x) \leq g_{i} \\
\frac{U_{i}-G_{i}(x)}{U_{i}-g_{i}} \text { if } g_{i} \leq G_{i}(x) \leq U_{i} \\
0 \text { if } G_{i}(x) \geq U_{i}
\end{array}\right.
$$

where: $L_{i}$ is the Upper tolerance limit for the fuzzy goal.

Now, the additive model of the FGP problem is formulated by adding the membership functions together as:

$$
\text { Maximize } V(\mu)=\sum_{i=1}^{m} \mu_{i}
$$

Subject to $\mu_{i}=\frac{G_{i}(x)-L_{i}}{g_{i}-L_{i}}$

$A X \leq b$

$\mu_{i} \leq 1$

$X, \mu_{i} \geq 0, I=1,2 \ldots, m$

where: $V(\mu)$ is called the fuzzy achievement function.

In this research, we utilize FGP to optimize the impact relations values of the SETs on operational objectives of the smart workplace (i.e., OOs). It means that every OO of the workplace will be considered as an individual goal, and the coefficient of the FGP are the positive impact values of each of the SET on that goal, in such a way that we seek to optimize the total positive impact of these SETs on these goals, OOs.

Next section, we present a case example for illustrating the application of the proposed smart workplace optimization procedure.

\section{Illustrative Workplace Case Example: Optimizing Design of Smart Clinic System}

In this case example, we shall demonstrate how the proposed methodology is practical and simple to apply. A clinic is currently investigating the potential of improving its operational performance through investing in SETs to develop a smart clinic environment. They have specified a set of operational objectives which are desired to improve. The clinic has two stories. The first story (See Figure 3a)) consists of 4 patient wards that can receive two patients each, Radiology and MRI room, a storeroom for medical equipment and consumables, nurses' room (used by two nurses on each $8 \mathrm{~h}$ shift), and the physicians' room 1 (used by 4 doctors on each shift). This is in addition to the clinic pharmacy, the operating room 1 , and finally the reception, cafeteria 1 , and garden yard. The second story layout (Figure 3b) is similar to the first story but includes 6 wards that can host a maximum of 10 patients, where wards 5 to 8 can host two patients, but wards 9 and 10 are equipped to host single patients depending on the patient case medical diagnostics. It includes also the operating room 2, the testing laboratory, the nurses' room 2 (used by 3 nurses on each shift), the physicians' room 2 (used by 6 doctors on each shift). The second story includes also the reception and cafeteria area beside a terrace. The total available budget is strictly limited to $\$ 50,000$. 


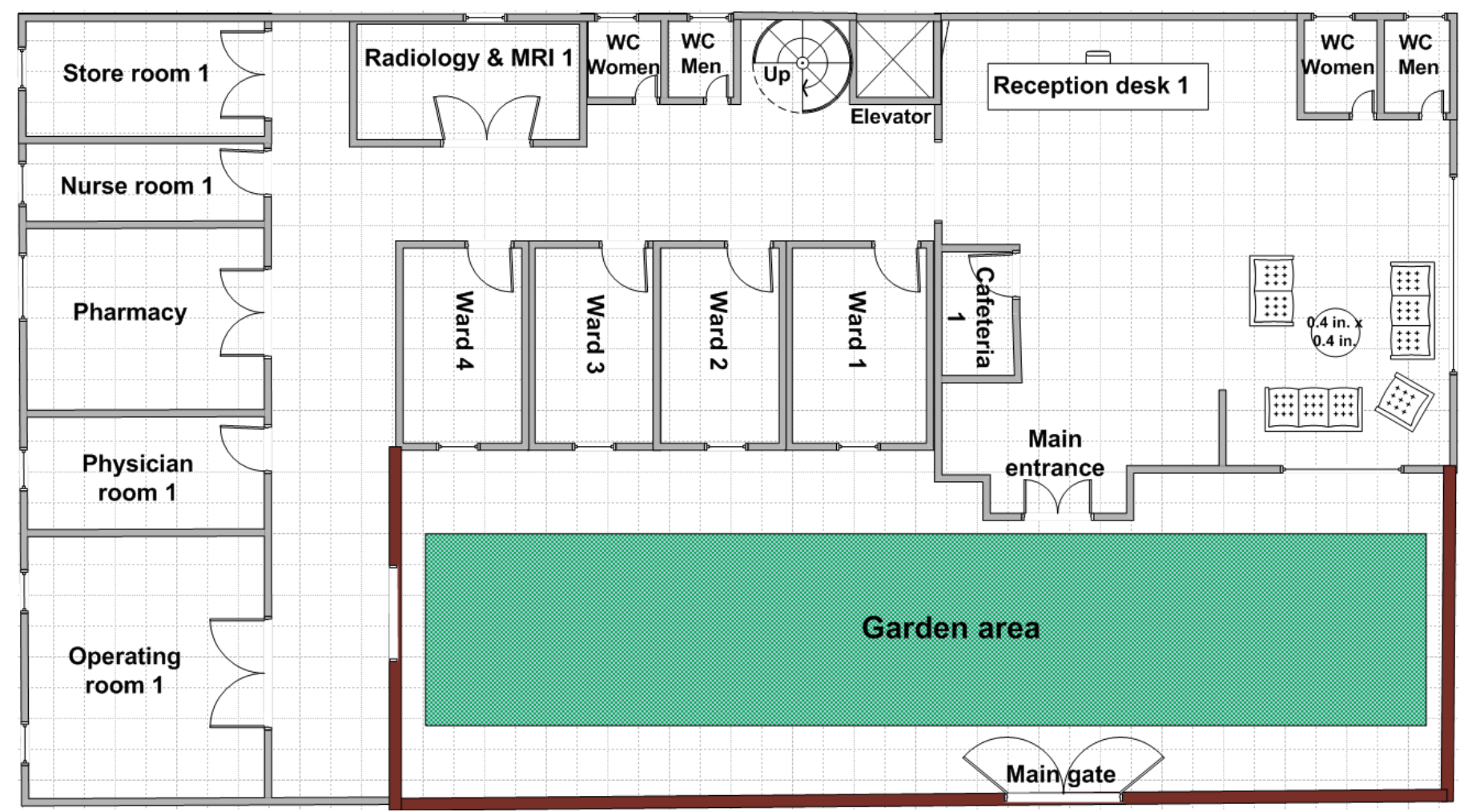

(a)

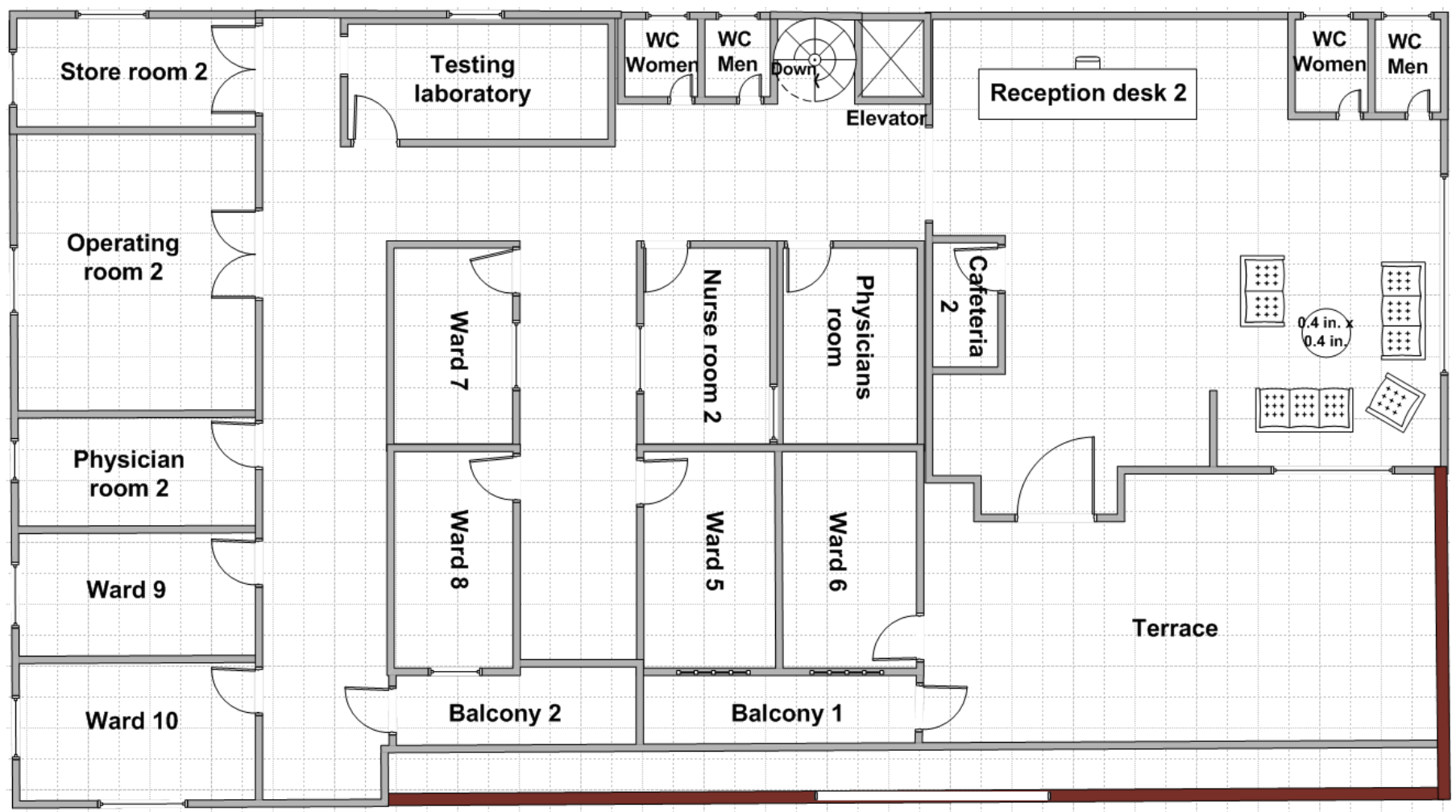

(b)

Figure 3. (a) One typical SETs deployment scenario on the first floor of the hospital. (b) One typical SETs deployment scenario on the first floor of the hospital.

Now, the proposed methodology is implemented as follows: 


\section{A. Defining model building blocks:}

The smart clinic workplace environment has correspondingly three model building blocks:

The smart enabling technologies (SETs): sensors, actuators, microcontrollers, and other basic software and hardware constituents that shall be installed in the clinic environment. (See Table 1 for the survey of the state of the art).

The clinic's smartness features (SFs): the intelligent characteristics, aspects, or attributes that will be introduced by installing the SETs.

The clinic's operational objectives (OOs): the objectives of the clinic's management operations and activities that are significant to achieve.

\section{B. Specifying workplace goals and objectives:}

Concerning the overall goals, interviewing the clinic's top management yielded the identification of two goals (OGs):

$\mathrm{OG}_{1}$ : Improving productivity $(\mathrm{P})$

$\mathrm{OG}_{2}$ : Enhancing Competitiveness (C)

Regarding the operational goals, interviewing the authoritative staff at the middle management identified the following seven clinic's operational objectives (OOs):

- $\mathrm{O}_{1}$ : Speed up patient check-in

- $\mathrm{O}_{2}$ : Optimize patient flow

- $\mathrm{O}_{3}$ : Enhance information support

- $\mathrm{O}_{4}$ : Speed up diagnosis

- $\mathrm{O}_{5}$ : Improve safety and security

- $\mathrm{O}_{6}$ : Minimize energy consumption

- $\mathrm{O}_{7}$ : Track people and assets

C. Ranking operational objectives:

In this step, we apply the PROMETHEE technique for ranking the clinic's operational objectives with respect to the overall goals. The expert decision-maker in the clinic has utilized a numerical rating scale from 0 to 10 to judge the importance of the OOs with respect to the clinic's overall goals (OGs) as indicated in Table A2 in Appendix B. The weights and thresholds are defined for each goal as shown in Table A3.

The preference function used is the Level function (See Table 1), as a typical function for demonstration in this illustrative example. In fact, the choice of a particular function depends on the decision maker's own view of the decision process. In general, the use of a threshold increases the reliability of the decision. In some circumstances, it is better to try several functions and then evaluate the results of each function based on the consistency and acceptance of the rating. The results of implementing the PROMETHEE technique are indicated in Table A4 in the Appendix B.

The normalized weights calculated in Table 1 for the operational objectives will be utilized in the objectives function's weighting coefficient in the fuzzy goal programming optimization model.

\section{List the smart enabling technologies (SETs):}

The result of the survey of state-of-the-art SETs is found in Table 1. This list contains 19 smart technology alternatives with various functionalities.

\section{E. List clinic's smartness features (SFs):}

The common smart clinic's healthcare features available from the literature have been studied and the most common addressed smartness attributes are listed as follows:

- $\quad \mathrm{F}_{1}$ : Location-aware asset tracking

- $\mathrm{F}_{2}$ : Patient/Staff location tracking

- $\quad \mathrm{F}_{3}$ : Patient/Staff Physiological activity monitoring and tracking

- $\mathrm{F}_{4}$ : Location-based services (patient, visitor, nurse, and physician)

- $\mathrm{F}_{5}$ : Automated patient check-in (no wait) 
- $\mathrm{F}_{6}$ : Indoor navigation

- $\mathrm{F}_{7}$ : Context-aware data and analytics

- $\mathrm{F}_{8}$ : Smart energy management

- $\mathrm{F}_{9}$ : Smart access and security

- $\mathrm{F}_{10}$ : Proactive safety response

- $\mathrm{F}_{11}$ : Multimodal/Natural interaction

\section{F. Construct the fuzzy relations among smart clinic's model building blocks:}

In this step, we quantify the fuzzy positive impact relation among the above three building blocks; namely: SETs, SFs and OOs. We construct the fuzzy "Positive impact" relations because these relations are not exact quantities and will be judged by human experts using the scale established in Table 3. Consequently, we can investigate two impact relations among these three sets. They are as follows:

- $\quad$ Relation 1: Smart enabling technologies (SET)-Smart features (SF).

- $\quad$ Relation 2: Smart Features (SF)-Operational objectives (OO).

Every relation is expressed as a fuzzy relation matrix of the positive impact among the two sets of elements. Mathematically, the three fuzzy matrices and the hierarchically composed matrices are defined as follows (see Figure 4):

Let

$R_{x}$ : Fuzzy impact relation matrix between the set of smart enabling technologies (SETs), $T_{i}$, and the set of clinic's smartness features (SFs), $F_{j}$

$R_{y}$ : Fuzzy relation matrix between the set of hospital smartness features (SFs), $F_{j}$, and the set of clinic's operational objectives (OOs), $O_{k}$.

$R_{z}$ : Max-Min composition of $R_{x}, R_{y}$ relations $\left(R_{z}=R_{x}{ }^{\circ} R_{y}\right)$ among the set of smart enabling technologies (SETs), $T_{i}$, and the set of clinic's operational objectives (OOs), $O_{k}$.

Table 3. Fuzzy relation matrix-SETs to SF "Positive impact" relations judgment.

\begin{tabular}{|c|c|c|c|c|c|c|c|c|c|c|c|}
\hline \multirow{2}{*}{ SET } & \multicolumn{11}{|c|}{ Smart Features (SFs) } \\
\hline & $F_{1}$ & $F_{2}$ & $F_{3}$ & $\mathrm{~F}_{4}$ & $F_{5}$ & $F_{6}$ & $F_{7}$ & $F_{8}$ & $F_{9}$ & $F_{10}$ & $F_{11}$ \\
\hline $\mathrm{T}_{1}$ & $\mathrm{H}$ & $E$ & M & $\mathrm{E}$ & $\mathrm{H}$ & $\mathrm{H}$ & $\mathrm{H}$ & $\mathrm{E}$ & $\mathrm{E}$ & $\mathrm{E}$ & $\mathrm{E}$ \\
\hline $\mathrm{T}_{2}$ & $E$ & $\mathrm{E}$ & $E$ & $\mathrm{E}$ & M & $\mathrm{V}$ & $\mathrm{S}$ & $\mathrm{N}$ & $S$ & $\mathrm{E}$ & $\mathrm{H}$ \\
\hline $\mathrm{T}_{3}$ & $E$ & $E$ & $\mathrm{H}$ & $\mathrm{E}$ & $\mathrm{H}$ & $\mathrm{E}$ & $\mathrm{H}$ & $\mathrm{M}$ & $\mathrm{H}$ & $\mathrm{E}$ & $\mathrm{E}$ \\
\hline $\mathrm{T}_{4}$ & $\mathrm{M}$ & $\mathrm{M}$ & $\mathrm{V}$ & $\mathrm{E}$ & $\mathrm{E}$ & $\mathrm{E}$ & $\mathrm{H}$ & $S$ & $S$ & $\mathrm{H}$ & $\mathrm{M}$ \\
\hline $\mathrm{T}_{5}$ & $\mathrm{H}$ & $\mathrm{H}$ & $\mathrm{H}$ & $S$ & $M$ & $\mathrm{M}$ & $\mathrm{S}$ & $\mathrm{V}$ & $\mathrm{E}$ & $\mathrm{E}$ & $\mathrm{H}$ \\
\hline $\mathrm{T}_{6}$ & $\mathrm{~N}$ & $\mathrm{~N}$ & $\mathrm{~N}$ & $\mathrm{M}$ & $\mathrm{H}$ & $\mathrm{H}$ & $\mathrm{S}$ & $\mathrm{H}$ & $\mathrm{E}$ & $\mathrm{M}$ & $S$ \\
\hline $\mathbf{T}_{7}$ & $\mathrm{~N}$ & $\mathrm{~N}$ & $\mathrm{~N}$ & $\mathrm{~N}$ & $\mathrm{~N}$ & $\mathrm{H}$ & $\mathrm{M}$ & $\mathrm{N}$ & $\mathrm{N}$ & $S$ & $\mathrm{~N}$ \\
\hline $\mathbf{T}_{8}$ & $\mathrm{~V}$ & $\mathrm{E}$ & $\mathrm{E}$ & $\mathrm{H}$ & $S$ & $\mathrm{E}$ & $\mathrm{H}$ & $S$ & $S$ & $\mathrm{H}$ & $\mathrm{M}$ \\
\hline $\mathrm{T}_{9}$ & $\mathrm{~N}$ & $\mathrm{~N}$ & $\mathrm{E}$ & $\mathrm{N}$ & $\mathrm{N}$ & $\mathrm{N}$ & $\mathrm{E}$ & $\mathrm{N}$ & $\mathrm{N}$ & $\mathrm{M}$ & E \\
\hline $\mathbf{T}_{10}$ & $\mathrm{~N}$ & $\mathrm{~N}$ & $\mathrm{E}$ & $\mathrm{N}$ & $\mathrm{N}$ & $\mathrm{N}$ & $E$ & $\mathrm{~N}$ & $\mathrm{~N}$ & $\mathrm{H}$ & $\mathrm{E}$ \\
\hline$T_{11}$ & $\mathrm{~N}$ & $\mathrm{~N}$ & $\mathrm{E}$ & $\mathrm{N}$ & $\mathrm{N}$ & $\mathrm{N}$ & $\mathrm{E}$ & $\mathrm{N}$ & $\mathrm{N}$ & $\mathrm{E}$ & $\mathrm{E}$ \\
\hline$T_{12}$ & $\mathrm{~N}$ & $\mathrm{~N}$ & $\mathrm{E}$ & $\mathrm{N}$ & $\mathrm{N}$ & $\mathrm{N}$ & $\mathrm{E}$ & $\mathrm{N}$ & $\mathrm{N}$ & $\mathrm{E}$ & $\mathrm{E}$ \\
\hline $\mathbf{T}_{13}$ & $\mathrm{~N}$ & $\mathrm{~N}$ & $\mathrm{E}$ & $\mathrm{N}$ & $\mathrm{N}$ & $\mathrm{N}$ & $\mathrm{S}$ & $\mathrm{N}$ & $\mathrm{N}$ & $\mathrm{E}$ & $\mathrm{E}$ \\
\hline$T_{14}$ & $\mathrm{E}$ & $\mathrm{N}$ & $\mathrm{N}$ & $\mathrm{E}$ & $\mathrm{N}$ & $\mathrm{N}$ & $\mathrm{M}$ & $\mathrm{N}$ & $\mathrm{N}$ & $\mathrm{E}$ & $\mathrm{E}$ \\
\hline $\mathbf{T}_{15}$ & $\mathrm{~N}$ & $\mathrm{~N}$ & $\mathrm{E}$ & $\mathrm{N}$ & $\mathrm{N}$ & $\mathrm{E}$ & $\mathrm{H}$ & $\mathrm{N}$ & $\mathrm{N}$ & $\mathrm{N}$ & $\mathrm{E}$ \\
\hline $\mathbf{T}_{16}$ & $\mathrm{~N}$ & $\mathrm{~N}$ & $\mathrm{E}$ & $S$ & $\mathrm{~N}$ & $\mathrm{E}$ & $\mathrm{H}$ & $\mathrm{N}$ & $\mathrm{N}$ & $\mathrm{H}$ & $\mathrm{E}$ \\
\hline $\mathbf{T}_{17}$ & $\mathrm{E}$ & $\mathrm{E}$ & $\mathrm{E}$ & $\mathrm{E}$ & $E$ & $\mathrm{E}$ & $\mathrm{E}$ & $E$ & $\mathrm{E}$ & $\mathrm{E}$ & $\mathrm{E}$ \\
\hline $\mathbf{T}_{18}$ & $E$ & $\mathrm{E}$ & $\mathrm{E}$ & $\mathrm{E}$ & $\mathrm{E}$ & $\mathrm{E}$ & $\mathrm{E}$ & $E$ & $\mathrm{E}$ & $\mathrm{E}$ & $\mathrm{E}$ \\
\hline$T_{19}$ & $\mathrm{E}$ & $\mathrm{E}$ & $\mathrm{E}$ & $\mathrm{E}$ & $\mathrm{E}$ & $\mathrm{E}$ & $\mathrm{E}$ & $E$ & $\mathrm{E}$ & $\mathrm{E}$ & E \\
\hline
\end{tabular}



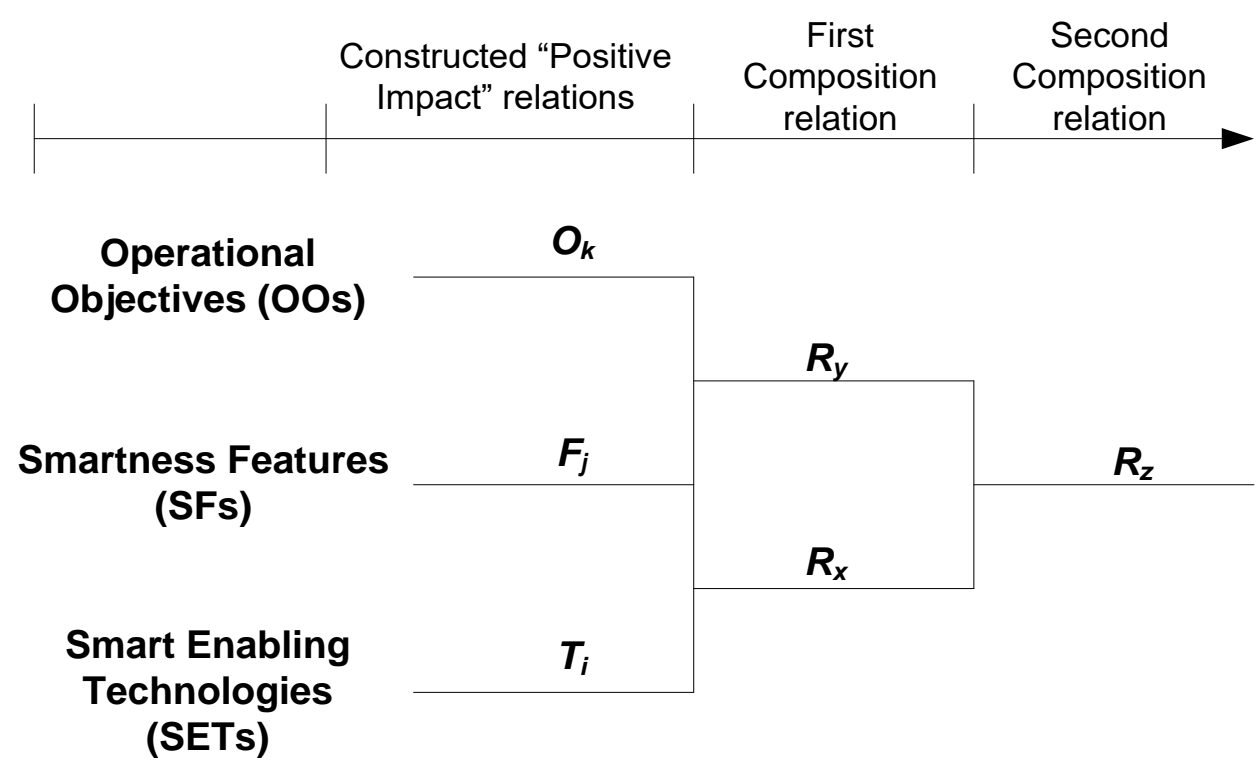

Figure 4. Compositions of fuzzy relations to attain the SETs-OOs composed fuzzy relation.

Tables 3-6 show the expert's assigned linguistic terms and corresponding numerical values for elements' pair-wise relation.

Table 4. Fuzzy relation matrix—SETs to SFs "Positively impact" relation-Numerical membership values.

\begin{tabular}{cccccccccccc}
\hline & & & & & & $\mathbf{S F}$ & & & & & \\
\hline $\mathbf{S E T}$ & $\mathbf{F}_{\mathbf{1}}$ & $\mathbf{F}_{\mathbf{2}}$ & $\mathbf{F}_{\mathbf{3}}$ & $\mathbf{F}_{\mathbf{4}}$ & $\mathbf{F}_{\mathbf{5}}$ & $\mathbf{F}_{\mathbf{6}}$ & $\mathbf{F}_{\mathbf{7}}$ & $\mathbf{F}_{\mathbf{8}}$ & $\mathbf{F}_{\mathbf{9}}$ & $\mathbf{F}_{\mathbf{1 0}}$ & $\mathbf{F}_{\mathbf{1 1}}$ \\
\hline $\mathbf{T}_{\mathbf{1}}$ & 0.8 & 1 & 0.6 & 1 & 0.8 & 0.8 & 0.8 & 1 & 1 & 1 & 1 \\
$\mathbf{T}_{\mathbf{2}}$ & 1 & 1 & 1 & 1 & 0.6 & 0.2 & 0.4 & 0 & 0.4 & 1 & 0.8 \\
$\mathbf{T}_{\mathbf{3}}$ & 1 & 1 & 0.8 & 1 & 0.8 & 1 & 0.8 & 0.6 & 0.8 & 1 & 1 \\
$\mathbf{T}_{\mathbf{4}}$ & 0.6 & 0.6 & 0.2 & 1 & 1 & 1 & 0.8 & 0.4 & 0.4 & 0.8 & 0.6 \\
$\mathbf{T}_{\mathbf{5}}$ & 0.8 & 0.8 & 0.8 & 0.4 & 0.6 & 0.6 & 0.4 & 0.2 & 1 & 1 & 0.8 \\
$\mathbf{T}_{\mathbf{6}}$ & 0 & 0 & 0 & 0.6 & 0.8 & 0.8 & 0.4 & 0.8 & 1 & 0.6 & 0.4 \\
$\mathbf{T}_{\mathbf{7}}$ & 0 & 0 & 0 & 0 & 0 & 0.8 & 0.6 & 0 & 0 & 0.4 & 0 \\
$\mathbf{T}_{\mathbf{8}}$ & 0.2 & 1 & 1 & 0.8 & 0.4 & 1 & 0.8 & 0.4 & 0.4 & 0.8 & 0.6 \\
$\mathbf{T}_{\mathbf{9}}$ & 0 & 0 & 1 & 0 & 0 & 0 & 1 & 0 & 0 & 0.6 & 1 \\
$\mathbf{T}_{\mathbf{1 0}}$ & 0 & 0 & 1 & 0 & 0 & 0 & 1 & 0 & 0 & 0.8 & 1 \\
$\mathbf{T}_{\mathbf{1 1}}$ & 0 & 0 & 1 & 0 & 0 & 0 & 1 & 0 & 0 & 1 & 1 \\
$\mathbf{T}_{\mathbf{1 2}}$ & 0 & 0 & 1 & 0 & 0 & 0 & 1 & 0 & 0 & 1 & 1 \\
$\mathbf{T}_{\mathbf{1 3}}$ & 0 & 0 & 1 & 0 & 0 & 0 & 0.4 & 0 & 0 & 1 & 1 \\
$\mathbf{T}_{\mathbf{1 4}}$ & 1 & 0 & 0 & 1 & 0 & 0 & 0.6 & 0 & 0 & 1 & 1 \\
$\mathbf{T}_{\mathbf{1 5}}$ & 0 & 0 & 1 & 0 & 0 & 1 & 0.8 & 0 & 0 & 0 & 1 \\
$\mathbf{T}_{\mathbf{1 6}}$ & 0 & 0 & 1 & 0.4 & 0 & 1 & 0.8 & 0 & 0 & 0.8 & 1 \\
$\mathbf{T}_{\mathbf{1 7}}$ & 1 & 1 & 1 & 1 & 1 & 1 & 1 & 1 & 1 & 1 & 1 \\
$\mathbf{T}_{\mathbf{1 8}}$ & 1 & 1 & 1 & 1 & 1 & 1 & 1 & 1 & 1 & 1 & 1 \\
$\mathbf{T}_{\mathbf{1 9}}$ & 1 & 1 & 1 & 1 & 1 & 1 & 1 & 1 & 1 & 1 & 1 \\
\hline
\end{tabular}


Table 5. Fuzzy relation matrix-SFs to OOs—Linguistic values judgments.

\begin{tabular}{|c|c|c|c|c|c|c|c|}
\hline \multirow{2}{*}{ SF } & \multicolumn{6}{|c|}{ OO } & \multirow[b]{2}{*}{$\mathrm{O}_{7}$} \\
\hline & $\mathrm{O}_{1}$ & $\mathrm{O}_{2}$ & $\mathrm{O}_{3}$ & $\mathrm{O}_{4}$ & $\mathrm{O}_{5}$ & $\mathrm{O}_{6}$ & \\
\hline$F_{1}$ & $\mathrm{H}$ & $\mathrm{H}$ & $\mathrm{H}$ & $\mathrm{N}$ & $\mathrm{E}$ & $\mathrm{H}$ & $\mathrm{E}$ \\
\hline$F_{2}$ & $\mathrm{H}$ & $\mathrm{H}$ & $\mathrm{E}$ & $S$ & $\mathrm{E}$ & $\mathrm{E}$ & $\mathrm{E}$ \\
\hline$F_{3}$ & $\mathrm{~N}$ & $\mathrm{~V}$ & E & $\mathrm{H}$ & $\mathrm{E}$ & $\mathrm{E}$ & $\mathrm{E}$ \\
\hline $\mathrm{F}_{4}$ & $\mathrm{H}$ & $\mathrm{H}$ & $\mathrm{E}$ & $S$ & $\mathrm{E}$ & $\mathrm{E}$ & $\mathrm{E}$ \\
\hline$F_{5}$ & $\mathrm{E}$ & $S$ & E & $\mathrm{N}$ & $\mathrm{H}$ & $\mathrm{N}$ & $\mathrm{N}$ \\
\hline$F_{6}$ & $\mathrm{~N}$ & $\mathrm{E}$ & $\mathrm{E}$ & $\mathrm{N}$ & $\mathrm{E}$ & $S$ & $\mathrm{H}$ \\
\hline $\mathrm{F}_{7}$ & $\mathrm{H}$ & $\mathrm{M}$ & E & E & $\mathrm{E}$ & $\mathrm{H}$ & $\mathrm{H}$ \\
\hline$F_{8}$ & $\mathrm{~N}$ & $\mathrm{~N}$ & $\mathrm{~N}$ & $\mathrm{~N}$ & $S$ & $\mathrm{E}$ & $\mathrm{E}$ \\
\hline$F_{9}$ & $\mathrm{H}$ & $\mathrm{M}$ & $\mathrm{H}$ & $\mathrm{N}$ & $\mathrm{E}$ & $\mathrm{N}$ & $\mathrm{E}$ \\
\hline$F_{10}$ & $\mathrm{H}$ & $\mathrm{H}$ & $\mathrm{H}$ & $\mathrm{M}$ & $\mathrm{H}$ & $\mathrm{H}$ & $\mathrm{E}$ \\
\hline$F_{11}$ & $\mathrm{M}$ & $S$ & $\mathrm{H}$ & $\mathrm{M}$ & $\mathrm{M}$ & $\mathrm{M}$ & V \\
\hline
\end{tabular}

Table 6. Fuzzy relation matrix-SFs to OOs-Numerical membership values.

\begin{tabular}{cccccccc}
\hline & \multicolumn{7}{c}{ Operational Objectives } \\
\cline { 2 - 8 } & $\mathbf{O}_{\mathbf{1}}$ & $\mathbf{O}_{\mathbf{2}}$ & $\mathbf{O}_{\mathbf{3}}$ & $\mathbf{O}_{\mathbf{4}}$ & $\mathbf{O}_{\mathbf{5}}$ & $\mathbf{O}_{\mathbf{6}}$ & $\mathbf{O}_{\mathbf{7}}$ \\
\hline $\mathbf{F}_{\mathbf{1}}$ & 0.8 & 0.8 & 0.8 & 0 & 1 & 0.8 & 1 \\
$\mathbf{F}_{\mathbf{2}}$ & 0.8 & 0.8 & 1 & 0.4 & 1 & 1 & 1 \\
$\mathbf{F}_{\mathbf{3}}$ & 0 & 0.2 & 1 & 0.8 & 1 & 1 & 1 \\
$\mathbf{F}_{\mathbf{4}}$ & 0.8 & 0.8 & 1 & 0.4 & 1 & 1 & 1 \\
$\mathbf{F}_{\mathbf{5}}$ & 1 & 0.4 & 1 & 0 & 0.8 & 0 & 0 \\
$\mathbf{F}_{\mathbf{6}}$ & 0 & 1 & 1 & 0 & 1 & 0.4 & 0.8 \\
$\mathbf{F}_{\mathbf{7}}$ & 0.8 & 0.6 & 1 & 1 & 1 & 0.8 & 0.8 \\
$\mathbf{F}_{\mathbf{8}}$ & 0 & 0 & 0 & 0 & 0.4 & 1 & 1 \\
$\mathbf{F}_{\mathbf{9}}$ & 0.8 & 0.6 & 0.8 & 0 & 1 & 0 & 1 \\
$\mathbf{F}_{\mathbf{1 0}}$ & 0.8 & 0.8 & 0.8 & 0.6 & 0.8 & 0.8 & 1 \\
$\mathbf{F}_{\mathbf{1 1}}$ & 0.6 & 0.4 & 0.8 & 0.6 & 0.6 & 0.6 & 0.2 \\
\hline
\end{tabular}

\section{G. Link SETs and OOs:}

In this step, to obtain the final target fuzzy relation between the clinic's OOs and the SETs, the widely used fuzzy relations max-min composition operator is utilized to compose the two constructed fuzzy relations: The relation between the SETs and SFs and the fuzzy relation between the SFs and OOs, was calculated as indicated Figure 4. This eventually leads to attaining target fuzzy relation between the OOs and the SETs that will be used as input to optimize the smart clinic design through maximizing the overall SETs positive impact on the operational objectives. This will be used as a guide for adopting the optimal SETs with high impact while satisfying the budget and other technical constraints. Now, using Equation (16) to compose the two relationships:

$$
\mu_{R_{z}}(x, z)=\max _{y \in Y}\left(\min \left(\mu_{R_{x}}(x, y), \mu_{R_{y}}(y, z)\right)\right)
$$

The result is computed in the same way as explained in example Section 4.2. The resulting matrix is as in Table 7 as follows: 
Table 7. Max-min composition Fuzzy relation matrices-SETs to OOs.

\begin{tabular}{cccccccc}
\hline & & & & OO & & & \\
\cline { 2 - 7 } $\mathbf{S E T}$ & $\mathbf{O}_{\mathbf{1}}$ & $\mathbf{O}_{\mathbf{2}}$ & $\mathbf{O}_{\mathbf{3}}$ & $\mathbf{O}_{\mathbf{4}}$ & $\mathbf{O}_{\mathbf{5}}$ & $\mathbf{O}_{\mathbf{6}}$ & $\mathbf{O}_{\mathbf{7}}$ \\
\hline $\mathbf{T}_{\mathbf{1}}$ & 0.8 & 0.8 & 1 & 0.8 & 1 & 1 & 1 \\
$\mathbf{T}_{\mathbf{2}}$ & 0.8 & 0.8 & 1 & 0.8 & 1 & 1 & 1 \\
$\mathbf{T}_{\mathbf{3}}$ & 0.8 & 1 & 1 & 0.8 & 1 & 1 & 1 \\
$\mathbf{T}_{\mathbf{4}}$ & 1 & 1 & 1 & 0.8 & 1 & 1 & 1 \\
$\mathbf{T}_{\mathbf{5}}$ & 0.8 & 0.8 & 0.8 & 0.8 & 1 & 0.8 & 1 \\
$\mathbf{T}_{\mathbf{6}}$ & 0.8 & 0.8 & 0.8 & 0.6 & 1 & 0.8 & 1 \\
$\mathbf{T}_{\mathbf{7}}$ & 0.6 & 0.8 & 0.8 & 0.6 & 0.8 & 0.6 & 0.8 \\
$\mathbf{T}_{\mathbf{8}}$ & 0.8 & 1 & 1 & 0.8 & 1 & 1 & 1 \\
$\mathbf{T}_{\mathbf{9}}$ & 0.8 & 0.6 & 1 & 1 & 1 & 1 & 1 \\
$\mathbf{T}_{\mathbf{1 0}}$ & 0.8 & 0.8 & 1 & 1 & 1 & 1 & 1 \\
$\mathbf{T}_{\mathbf{1 1}}$ & 0.8 & 0.8 & 1 & 1 & 1 & 1 & 1 \\
$\mathbf{T}_{\mathbf{1 2}}$ & 0.8 & 0.8 & 1 & 1 & 1 & 1 & 1 \\
$\mathbf{T}_{\mathbf{1 3}}$ & 0.8 & 0.8 & 1 & 0.8 & 1 & 1 & 1 \\
$\mathbf{T}_{\mathbf{1 4}}$ & 0.8 & 0.8 & 1 & 0.6 & 1 & 1 & 1 \\
$\mathbf{T}_{\mathbf{1 5}}$ & 0.8 & 0 & 1 & 0.8 & 1 & 1 & 1 \\
$\mathbf{T}_{\mathbf{1 6}}$ & 0.8 & 0 & 1 & 0.8 & 1 & 1 & 1 \\
$\mathbf{T}_{\mathbf{1 7}}$ & 1 & 1 & 1 & 1 & 1 & 1 & 1 \\
$\mathbf{T}_{\mathbf{1 8}}$ & 1 & 1 & 1 & 1 & 1 & 1 & 1 \\
$\mathbf{T}_{\mathbf{1 9}}$ & 1 & 1 & 1 & 1 & 1 & 1 & 1 \\
\hline
\end{tabular}

\section{H. Develop SETs deployment scenario:}

The SETs deployment scenario depends on multiple factors. First, the functionality, applicability, and capabilities of each technology, besides the possible synergies with other technologies. This of course affects the location and number of technologies hardware and software deployed. It is also influenced by the operational objectives and tasks of activities and operations. There can be multiple deployment scenarios showing a different way of employing the SETs. Each scenario utilizes all or partial groups of SETs and yields a corresponding costs requirement (See Table 8) and has different functional impacts and priorities on the hospital operational performance. One logical deployment scenario (See excerpts in Figure $5 \mathrm{a}, \mathrm{b}$ ) is as follows:

- The motion sensor is deployed close to each door to detect motion, which triggers the RFID reader to identify people or assets in its proximity and to read attached tags information.

- The outdoor tracking system can be used to locate and pick up patients in the vicinity of the hospital.

- The indoor navigation system is implemented by a system utilizing low energy blue tooth i-beacon to support the patients and visitors with accurate navigation routes throughout the hospital building. The i-beacon is located in distinctive location points to guide people in hospital navigation.

- The video camera (CCTV) is deployed at the terminal or ends of the corridors and hospital rooms for surveillance purposes.

- A speech recognition system can be implemented to serve as a natural communication and control alternative for persons with physical disabilities or handicapped patients and visitors.

- $\quad$ The head-mounted display (HMD) system is utilized in surgery to enhance visualization and improve the reliability of diagnosis and operations.

- The smartwatch provides for patients, and staff, indoor and positioning, tracking some physiological parameters and can act as a fall detector.

- The physiological sensors monitor health parameters. EMG sensor is needed for monitoring muscle malfunctioning of patients. ECG sensor is needed for monitoring the heartbeat of patients.

- The thermometers monitor the temperature of patients. 
- The activity trackers monitor several physiological and various health parameters like heartbeat rate, blood pressure, etc., of the patients and staff.

- $\quad$ Special needs technologies such as the computer-brain interface (CBI) and eye trackers systems can be used for physically impaired persons.

- Smoke detectors detect fire hazards and are deployed in each room of the hospital.

- $\quad$ Fall detectors sense patient fall situations and are attached to every patient.

- The bed pressure sensors are attached to every bed in the hospital to detect when patients wake up.

- The WiFi routers enable internet service inside the hospital's locations. The Bluetooth scanners can be used to securely transfer patients' data inside the hospital building.

- The control system includes two microcontrollers gateways installed on the two floors of the hospital.

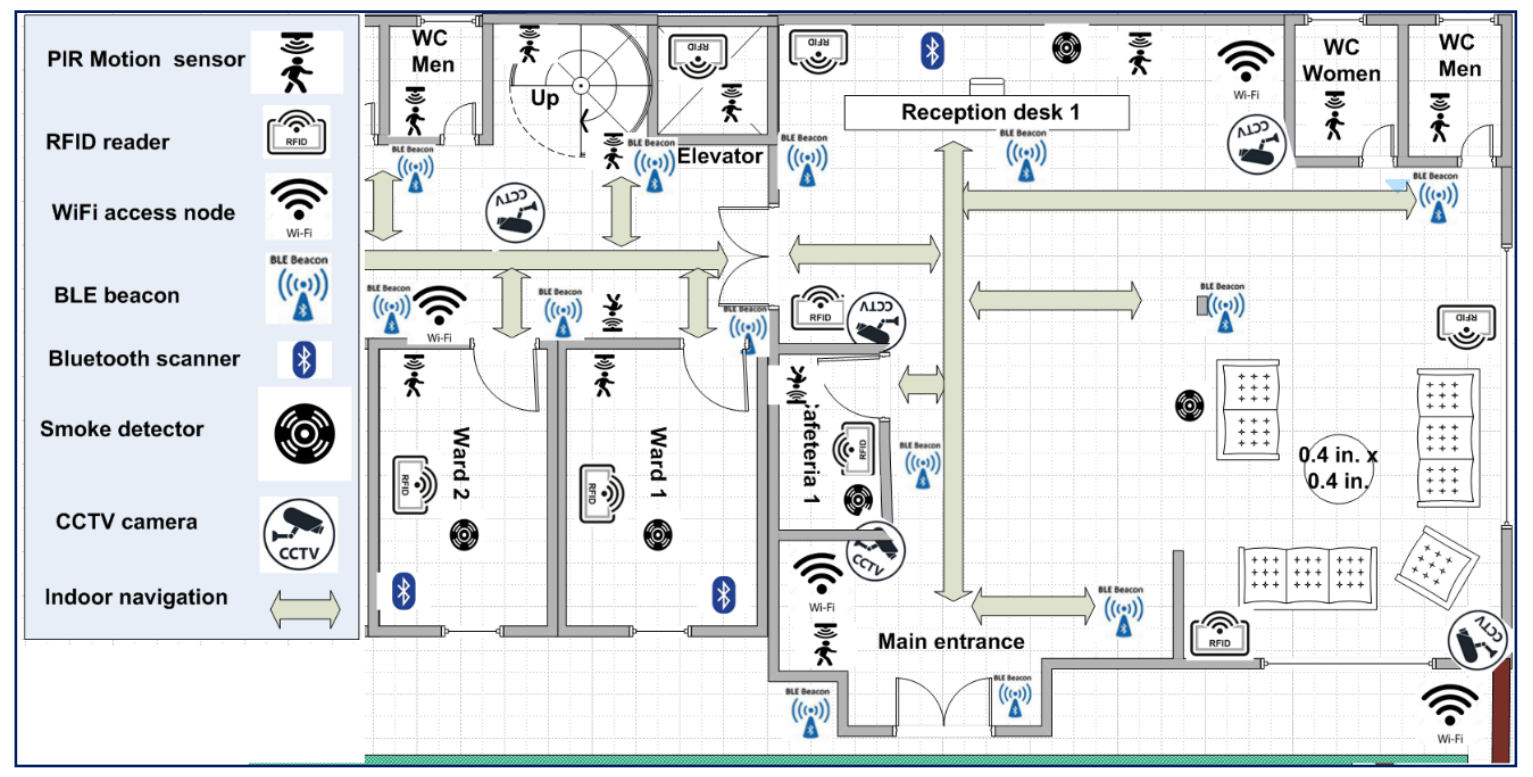

(a)

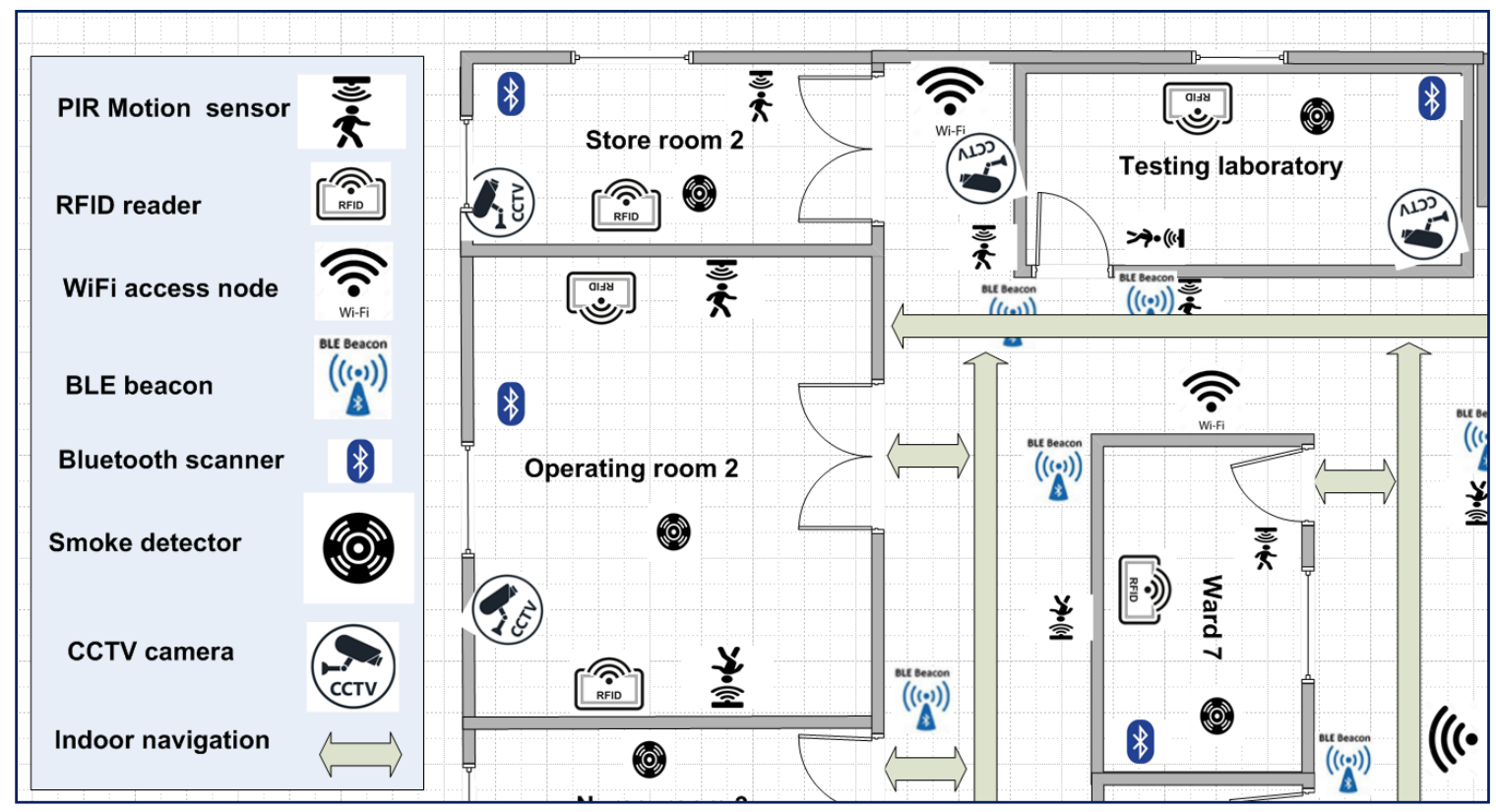

(b)

Figure 5. (a) One typical SETs deployment scenario on the first floor of the hospital. (b) One typical SETs deployment scenario on the second floor of the hospital. 
Table 8. The cost implication of SETs deployment scenario.

\begin{tabular}{|c|c|c|c|c|}
\hline SET & Number Needed & Actual Cost/Unit & Deployment Details & Total Cost \\
\hline $\begin{array}{c}\mathrm{T}_{1} \text { : Motion sensor (e.g., PIR } \\
\text { motion sensor) }\end{array}$ & 56 & $\$ 50$ & $\begin{array}{l}56 \text { motion sensors for detecting } \\
\text { the presence of people to alert } \\
\text { and energy saving as well }\end{array}$ & $\$ 2800$ \\
\hline $\mathrm{T}_{2}$ : Outdoor positioning system & 1 & $\$ 100$ & $\begin{array}{l}\text { A subscription software to track } \\
\text { patients, outdoor (e.g., garden, } \\
\text { neighborhood locations }\end{array}$ & $\$ 100$ \\
\hline $\mathrm{T}_{3}:$ RFID Tag/Reader & 39 & $\$ 200$ & $\begin{array}{l}18 \text { and } 21 \text { RFID readers (total 39) } \\
\text { on the first and second floors, } \\
\text { respectively. Tags are attached to } \\
\text { patients, staff, visitors, assets for } \\
\text { tracking and identifying patients, } \\
\text { staff, and assets at all locations. }\end{array}$ & $\$ 7800$ \\
\hline $\mathrm{T}_{4}$ : Indoor navigation system & 38 & $\$ 25$ & $\begin{array}{l}38 \text { low energy Bluetooth beacon } \\
\text { to provide for indoor navigation }\end{array}$ & $\$ 950$ \\
\hline $\begin{array}{c}\mathrm{T}_{5} \text { : Video camera (e.g., } \\
\text { Monocular/3D stereo camera) }\end{array}$ & 21 & $\$ 275$ & $\begin{array}{l}26 \text { CCTV continuously monitors } \\
\text { the corridor and storerooms, } \\
\text { balcony, garden, and gates, etc. }\end{array}$ & $\$ 5775$ \\
\hline $\begin{array}{c}\mathrm{T}_{6}: \text { Speech/voice recognition } \\
\text { interface }\end{array}$ & 1 & $\$ 3000$ & $\begin{array}{l}\text { Speech recognition modules for } \\
\text { controlling wheel chairs, etc. }\end{array}$ & $\$ 3000$ \\
\hline $\begin{array}{l}\mathrm{T}_{7} \text { : Head Mounted Display } \\
\text { (HMD) }\end{array}$ & 4 & $\$ 200$ & $\begin{array}{c}4 \text { HMD for use to enhance } \\
\text { visualization in } \\
\text { surgeries/checks. }\end{array}$ & $\$ 800$ \\
\hline $\mathrm{T}_{8}:$ Smart watch & 49 & $\$ 350$ & $\begin{array}{l}16 \text { patients }+15 \text { nurses }+18 \\
\text { doctors }\end{array}$ & $\$ 17,150$ \\
\hline $\mathrm{T}_{9}$ : EMG (Electromyography) & 1 & $\$ 10,000$ & $\begin{array}{l}\text { EMG sensor is needed for } \\
\text { detecting muscles } \\
\text { malfunctioning patients }\end{array}$ & $\$ 10,000$ \\
\hline $\mathrm{T}_{10}: \mathrm{ECG}$ & 2 & $\$ 220$ & $\begin{array}{l}5 \text { ECG sensors monitor } \\
\text { heartbeats of patients }\end{array}$ & $\$ 440$ \\
\hline $\mathrm{T}_{11}$ : Temperature thermometer & 16 & $\$ 100$ & $\begin{array}{c}16 \text { thermometers monitor } 16 \\
\text { patients }\end{array}$ & $\$ 1600$ \\
\hline $\mathrm{T}_{12}$ : Activity Tracker Wearables & 16 & $\$ 50$ & 16 patients tracking are required & $\$ 800$ \\
\hline $\begin{array}{c}\mathrm{T}_{13}: \text { Computer brain interface } \\
(\mathrm{CBI})\end{array}$ & 2 & $\$ 200$ & $\begin{array}{l}2 \text { CBI systems will be kept for } \\
\text { special needs case }\end{array}$ & $\$ 400$ \\
\hline $\mathrm{T}_{14}$ : Eye-tracking system & 1 & $\$ 10,000$ & $\begin{array}{l}\text { Eye-tracking wheelchair for } \\
\text { special needs case }\end{array}$ & $\$ 10,000$ \\
\hline $\mathrm{T}_{15}:$ Smoke detector & 39 & $\$ 40$ & $\begin{array}{l}28 \text { smoke detectors are installed } \\
\text { to protect rooms against fire. }\end{array}$ & $\$ 1560$ \\
\hline $\mathrm{T}_{16}:$ Fall detector & 16 & $\$ 70$ & 16 patients & $\$ 1120$ \\
\hline $\mathrm{T}_{17}:$ Bed pressure sensor & 16 & $\$ 120$ & 16 patients' bed & $\$ 1920$ \\
\hline $\begin{array}{l}\mathrm{T}_{18}: \text { WiFi router }+ \text { Bluetooth } \\
\text { scanner }\end{array}$ & $\begin{array}{c}14 \mathrm{WiFi}+24 \\
\text { Bluetooth scanner }\end{array}$ & $\$ 400+\$ 80$ & $\begin{array}{l}\text { The WiFi routers provide the } \\
\text { internet service inside the } \\
\text { hospital. The Bluetooth scanners } \\
\text { can be used securely transfer } \\
\text { patients' data inside the hospital }\end{array}$ & $\$ 7520$ \\
\hline $\begin{array}{c}\mathrm{T}_{19} \text { : Control system (e.g., Home } \\
\text { Gateway, etc.) }\end{array}$ & 2 & $\$ 1200$ & $\begin{array}{l}2 \text { microcontroller gateways (in } \\
\text { the two stories) }\end{array}$ & $\$ 2400$ \\
\hline
\end{tabular}


Now, the next step involves conducting the optimization step using the computed data from the previous steps, including the weights of OOs, the positive impacts of SETs on OOs of the clinic workplace, and the total cost of each individual SETs obtained from a typically proposed scenario.

\section{Formulate fuzzy goal programming (FGP)}

Goal programming begins with defining the basic model decision variables [36], then the formulation of fuzzy goals, followed by formulating the fuzzy goal programming model as follows:

(a) Defining decision variables:

$$
X_{i}=\left\{\begin{array}{l}
1 \text { if } i^{\text {th }} \text { If smart technology, } T_{i} \text { is adopted } \\
0 \text { Otherwise }
\end{array}\right.
$$

where: $i=1,2, \ldots, 19$. Index 1 refers to the motion sensor, $T_{1}$, and so on.

(b) The initial formulation of goal inequalities:

The goals of maximizing positive impacts of SETs on the OOs extracted from the resultant matrix in Table 8 are expressed in form of inequalities. The target levels represent fuzzy inspiration quantities, expressed by the symbols $\gtrsim$ or $\lesssim$, depending on either maximization or minimization. Here, we have to maximize total positive impact, so they are set to equal $90 \%$ of total maximum possible impact ever when all the SETs are adopted, 19 (i.e., 19 SETs, each of which has a maximum impact equal to 1 ) which is equal 17.1. Of course, an achievement which is restricted by the budget limit for the project (i.e., $\$ 50,000$ ). Hence our target is 17.1 as shown below.

Goal 1: Attain the maximum target positive impact level on "Speed-up patient check-in" objective:

$$
\begin{gathered}
0.8 X_{1}+0.8 X_{2}+0.8 X_{3}+X_{4}+0.8 X_{5}+0.8 X_{6}+0.6 X_{7}+0.8 X_{8}+0.8 X_{9}+0.8 \\
X_{10}+0.8 X_{11}+0.8 X_{12}+0.8 X_{13}+0.8 X_{14}+0.8 X_{15}+0.8 X_{16}+\mathrm{I}_{17}+0.8 X_{18}+ \\
0.8 X_{19} \gtrsim 17.1
\end{gathered}
$$

Goal 2: Attain the maximum target positive impact level on "Optimize patient flow" objective:

$$
\begin{gathered}
0.8 X_{1}+0.8 X_{2}+X_{3}+X_{4}+0.8 X_{5}+0.8 X_{6}+0.8 X_{7}+X_{8}+0.6 X_{9}+0.8 X_{10}+0.8 \\
X_{11}+0.8 X_{12}+0.8 X_{13}+0.8 X_{14}+X_{15}+X_{16}+X_{17}+X_{18}+X_{19} \gtrsim 17.1
\end{gathered}
$$

Goal 3: Attain the maximum target positive impact on the "Enhancing information support" objectives:

$$
\begin{gathered}
X_{1}+X_{2}+X_{3}+X_{4}+0.8 X_{5}+0.8 X_{6}+0.8 X_{7}+X_{8}+X_{9}+X_{10}+X_{11}+X_{12}+X_{13}+X_{14} \\
+X_{15}+X_{16}+X_{17}+X_{18}+X_{19} \gtrsim 17.1
\end{gathered}
$$

Goal 4: Attain the maximum target positive impact on the "Speed up diagnosis" objectives:

$$
\begin{gathered}
0.8 X_{1}+0.8 X_{2}+0.8 X_{3}+0.8 X_{4}+0.8 X_{5}+0.6 X_{6}+0.6 X_{7}+0.8 X_{8}+X_{9}+X_{10}+ \\
X_{11}+X_{12}+0.8 X_{13}+0.6 X_{14}+0.8 X_{15}+0.8 X_{16}+X_{17}+X_{18}+X_{19} \gtrsim 17.1
\end{gathered}
$$

Goal 5: Attain the maximum target positive impact on the "Improve safety and security" objectives:

$$
\begin{gathered}
X_{1}+X_{2}+X_{3}+X_{4}+X_{5}+X_{6}+0.8 X_{7}+X_{8}+X_{9}+X_{10}+X_{11}+X_{12}+X_{13}+X_{14}+X_{15}+ \\
X_{16}+X_{17}+X_{18}+X_{19} \gtrsim 17.1
\end{gathered}
$$


Goal 6: Attain the maximum target positive impact on the "Minimize energy consumption" objectives:

$$
\begin{gathered}
X_{1}+X_{2}+X_{3}+X_{4}+0.8 X_{5}+0.8 X_{6}+0.6 X_{7}+X_{8}+X_{9}+X_{10}+X_{11}+X_{12}+X_{13}+X_{14} \\
+X_{15}+X_{16}+X_{17}+X_{18}+X_{19} \gtrsim 17.1
\end{gathered}
$$

Goal 7: Attain the maximum target positive impact on the "Track people and assets" objectives:

$$
\begin{gathered}
X_{1}+X_{2}+X_{3}+X_{4}+X_{5}+X_{6}+0.8 X_{7}+X_{8}+X_{9}+X_{10}+X_{11}+X_{12}+X_{13}+X_{14}+X_{15} \\
+X_{16}+X_{17}+X_{18}+X_{19} \gtrsim 17.1
\end{gathered}
$$

\section{Constraints:}

Constraint 1: Satisfy budget constraint:

$$
\begin{gathered}
28 X_{1}+X_{2}+78 X_{3}+9.5 X_{4}+57.75 X_{5}+30 X_{6}+8 X_{7}+171.5 X_{8}+100 X_{9}+4.4 \\
X_{10}+16 X_{11}+8 X_{12}+4 X_{13}+100 X_{14}+15.6 X_{15}+11.2 X_{16}+19.2 X_{17}+75.2 X_{18}+ \\
24 X_{19} \leq 500
\end{gathered}
$$

Constraint 2: Complementarity of the motion and RFID sensors constraint: This constraint necessitates that the motion sensors and RFID readers must exit together since the motion sensor detects presence and RFID identifies people or assets through reading the information in the tag attached to the person or the object, whose presence has been detected.

$$
X_{1}+X_{3} \geq 2
$$

Constraint 3: The decision variables possible values:

$$
X_{i} \geq 0(\text { Binary }(0,1))
$$

(c) Fuzzy Goal Programming formulation model for optimization of smart clinic workplace:

The FGP model is formulated by specifying the fuzzy achievement function, linear membership function for each fuzzy goal, and other constraints using Equations (18)-(21). Here, we have 7 goals corresponding to the 7 operational objectives. Before stating FGP, it is necessary to define lower bounds (in case of goal maximization or type fuzzy aspiration) and upper bound (in case of goal maximization or $\lesssim$ type fuzzy aspiration). This is done by the decision-maker who assigns lower bounds on achieving target operational objectives' on a positive impact level. In this case, it is supposed that the decision analyst decided that the lower bounds are equal to $70 \%$ of the total maximum possible impact ever (i.e., $0.7 \times 19 \approx 13.5)$, but generally, they can differ depending on the viewpoint of the decisionmaker. The weights of fuzzy goals are obtained by the implementation of the PROMETHEE MCDM technique in stage 3 (See Table A4 in Appendix B).

The FGP formulation is as follows:

Objective function:

$$
\begin{gathered}
\text { Maximize } V(\mu)=\sum_{i=1}^{m} W_{i} \mu_{i}=\sum_{i=1}^{7} W_{i} \mu_{i} \\
\text { Maximize } V(\mu)=0.21 \mu_{1}+0.19 \mu_{2}+0.11 \mu_{3}+0.19 \mu_{4}+0.13 \mu_{5}+0.09 \mu_{6}+ \\
0.07 \mu_{7}
\end{gathered}
$$

Subject to:

$$
\mu_{i}=\frac{G_{i}(x)-L_{i}}{g_{i}-L_{i}}=\frac{G_{i}(x)-13.5}{17.1-13.5}, I=1,2, \ldots \ldots, 7
$$




$$
3.6 \mu_{i}-G_{i}(x)=-13.5
$$

Fuzzy goal 1: Attain the maximum target positive impact level on "Speed-up patient check-in" objective:

$$
\begin{gathered}
3.6 \mu_{1}-0.8 X_{1}-0.8 X_{2}-0.8 X_{3}-X_{4}-0.8 X_{5}-0.8 X_{6}-0.6 X_{7}-0.8 X_{8}-0.8 X_{9} \\
-0.8 X_{10}-0.8 X_{11}-0.8 X_{12}-0.8 X_{13}-0.8 X_{14}-0.8 X_{15}-0.8 X_{16}-X_{17}-0.8 X_{18}- \\
0.8 X_{19}=-13.5
\end{gathered}
$$

Fuzzy goal 2: Attain the maximum target positive impact level on "Optimize patient flow" objective:

$$
\begin{gathered}
3.6 \mu_{2}-0.8 X_{1}-0.8 X_{2}-X_{3}-X_{4}-0.8 X_{5}-0.8 X_{6}-0.8 X_{7}-X_{8}-0.6 X_{9}-0.8 \\
X_{10}-0.8 X_{11}-0.8 X_{12}-0.8 X_{13}-0.8 X_{14}-X_{15}-X_{16}-X_{17}-X_{18}-X_{19}=-13.5
\end{gathered}
$$

Fuzzy goal 3: Attain the maximum target positive impact on the "Enhancing information support" objective:

$$
\begin{gathered}
3.6 \mu_{3} X_{1}-X_{2}-X_{3}-X_{4}-0.8 X_{5}-0.8 X_{6}-0.8 X_{7}-X_{8}-X_{9}-X_{10}-X_{11}-X_{12}- \\
X_{13}-X_{14}-X_{15}-X_{16}-X_{17}-X_{18}-X_{19}=-13.5
\end{gathered}
$$

Fuzzy goal 4: Attain the maximum target positive impact on the "Speed up diagnosis" objectives:

$$
\begin{aligned}
& 3.6 \mu_{4}-0.8 X_{1}-0.8 X_{2}-0.8 X_{3}-0.8 X_{4}-0.8 X_{5}-0.6 X_{6}-0.6 X_{7}-0.8 X_{8}-X_{9} \\
- & X_{10}-X_{11}-X_{12}-0.8 X_{13}-0.6 X_{14}-0.8 X_{15}-0.8 X_{16}-X_{17}-X_{18}-X_{19}=-13.5
\end{aligned}
$$

Fuzzy goal 5: Attain the maximum target positive impact on the "Improve safety and security" objectives:

$$
\begin{gathered}
3.6 \mu_{5}-X_{1}-X_{2}-X_{3}-X_{4}-X_{5}-X_{6}-0.8 X_{7}-X_{8}-X_{9}-X_{10}-X_{11}-X_{12} \\
-X_{13}-X_{14}-X_{15}-X_{16}-X_{17}-X_{18}-X_{19}=-13.5
\end{gathered}
$$

Fuzzy goal 6: Attain the maximum target positive impact on the "Minimize energy consumption" objectives:

$$
\begin{gathered}
3.6 \mu_{6}-X_{1}-X_{2}-X_{3}-X_{4}-0.8 X_{5}-0.8 X_{6}-0.6 X_{7}-X_{8}-X_{9}-X_{10}-X_{11}-X_{12}- \\
X_{13}-X_{14}-X_{15}-X_{16}-X_{17}-X_{18}-X_{19}=-13.5
\end{gathered}
$$

Fuzzy goal 7: Attain the maximum target positive impact on the "Track people and assets" objectives:

$$
\begin{gathered}
3.6 \mu_{7}-X_{1}-X_{2}-X_{3}-X_{4}-X_{5}-X_{6}-0.8 X_{7}-X_{8}-X_{9}-X_{10}-X_{11}-X_{12}-X_{13}- \\
X_{14}-X_{15}-X_{16}-X_{17}-X_{18}-X_{19}=-13.5
\end{gathered}
$$

\section{Constraints:}

$$
\begin{gathered}
2800 X_{1}+100 X_{2}+7800 X_{3}+950 X_{4}+5775 X_{5}+3000 X_{6}+800 X_{7}+17,150 X_{8}+ \\
100 X_{9}+4400 X_{10+}+1600 X_{11}+800 X_{12}+400 X_{13}+10,000 X_{14}+1560 X_{15}+1120 \\
X_{16}+1920 X_{17}+7520 X_{18}+2400 X_{19} \leq 50,000 \\
X_{1}+X_{3} \geq 2 \\
\mu_{i} \geq 0, i=1,2, \ldots 7 . \\
0 \leq \mu_{i} \leq 1 \\
X_{i} \geq 0, i=1,2, \ldots 7 . X_{i} \text { is binary }(0,1) \\
\mu_{1}=0.08, \mu_{2}=0.31, \mu_{3}=0.81, \mu_{4}=0.31, \mu_{5}=0.92, \\
\mu_{6}=0.75, \mu_{7}=0.92 .
\end{gathered}
$$




$$
\begin{gathered}
X_{1}=1, X_{2}=1, X_{3}=1, X_{4}=1, X_{5}=1, X_{6}=1, X_{7}=1, X_{8}=0, X_{9}=1, X_{10}=1, X_{11}=1, X_{12}=1, \\
X_{13}=1, X_{14}=0, X_{15}=1, X_{16}=1, X_{17}=1, X_{18}=1, X_{19}=1
\end{gathered}
$$

This model is solved by mixed integer programming branch and bound algorithm using TORA software [39]. The results are as follows:

Objective Value $=4.08(\mathrm{MAX})$. The optimal values of the FGP variables are as follows:

$$
\begin{gathered}
\mu_{1}=0.08, \mu_{2}=0.31, \mu_{3}=0.81, \mu_{4}=0.31, \mu_{5}=0.92, \\
\mu_{6}=0.75, \mu_{7}=0.92 .
\end{gathered}
$$

The basic variables' values:

$$
\begin{gathered}
X_{1}=1, X_{2}=1, X_{3}=1, X_{4}=1, X_{5}=1, X_{6}=1, X_{7}=1, X_{8}=0, X_{9}=1, X_{10}=1, X_{11}=1, \\
X_{12}=1, X_{13}=1, X_{14}=0, X_{15}=1, X_{16}=1, X_{17}=1, X_{18}=1, X_{19}=1
\end{gathered}
$$

The result implied that the SETs smartwatch $\left(T_{8}\right)$ and Eye tracker system $\left(T_{14}\right)$ have not been adopted by the optimization process, as their values are equal to 0 . All other technologies were adopted, and the budget constraint is satisfied. The analysis of achievement against the target levels is indicated in Table 9 below.

Table 9. Analysis of goal achievements.

\begin{tabular}{cccccc}
\hline Goal No. & Description & $\begin{array}{c}\text { Fuzzy Target } \\
\text { Level }\end{array}$ & $\begin{array}{c}\text { Lower Bound } \\
\text { (Limit) }\end{array}$ & $\begin{array}{c}\text { Achieved } \\
\text { Value }\end{array}$ & $\begin{array}{c}\text { Achieved } \\
\text { (\%) }\end{array}$ \\
\hline 1 & $\begin{array}{c}\text { Speed-up patient } \\
\text { check-in }\end{array}$ & 17.1 & 13.5 & 16.8 & 98.2 \\
\hline 2 & $\begin{array}{c}\text { Optimize patient } \\
\text { flow }\end{array}$ & 17.1 & 13.5 & 14.8 & 86.5 \\
\hline 3 & $\begin{array}{c}\text { Enhancing } \\
\text { information } \\
\text { support }\end{array}$ & 17.1 & 13.5 & 17.4 & 100 \\
\hline 4 & $\begin{array}{c}\text { Speed up } \\
\text { diagnosis }\end{array}$ & 17.1 & 13.5 & 14.6 & 85.4 \\
\hline 5 & $\begin{array}{c}\text { Improve safety } \\
\text { and security }\end{array}$ & 17.1 & 13.5 & 16.8 & 98.2 \\
\hline 6 & $\begin{array}{c}\text { Minimize energy } \\
\text { consumption }\end{array}$ & 17.1 & 13.5 & 16.2 & 94.7 \\
\hline 7 & $\begin{array}{c}\text { Track people and } \\
\text { assets }\end{array}$ & 19 & 13.5 & 17.8 & 100 \\
\hline & $\quad$ & & & \\
\hline
\end{tabular}

The analysis of the results of applying the FGP model is indicated in Table 9, where the workplace goals (Operational objectives) 3 and 7 only have been totally achieved, whereas other goals, 1, 2, 4, 5, 6 were partially satisfied. The average achievement level is computed by taking the average of the achieved percentages of the 7 operational objectives, which is equal to $94.7 \%$.

In fact, the FGP model has enabled achieving all the constraints flexibly while optimizing the objective function. The model can include multiple constraints according to the relationships among the technologies concerning their interoperability, synergies, or even conflict, through mathematical expressions. It also can enable the utilization of qualitative goals not only quantitative ones.

\section{J. Assess SETs actual performance}

The implementation of the proposed methodology's nine steps is followed by the tenth step which is the assessment of the actual performance of the SETs after deployment. In this way we have a cycle that continues to improve performance with respect to goal 
achievement, to provide for handling updates in the SETs, and to conduct re-optimization of the design of the smart clinic.

\section{Conclusions}

Currently, there is a lack of systematic optimization procedures for developing smart environments. This paper presents a pioneering step toward optimizing smart environment designs, particularly for workplaces. In this research, we have presented a systematic procedure that works under ambiguous conditions. Fuzzy relations were used to model and quantify impact relationships among the three basic workplace model building blocks: OOs, SFs, and SETs. The proposed procedure optimizes the adoption of the SETs utilizing the fuzzy goal programming model to maximize the positive impact of the selected SETs in the smart workplace design. Using a basic mathematical modeling paradigm, the proposed methodology can take on additional constraints including the conditional relationship among goals, technologies, and even the smart features that all can be easily included in the model.

Even though the proposed procedure combines several basic techniques; namely: multi-criterion decision-making tool (PROMETHEE), Fuzzy relations, and Fuzzy goal programming, its use, and computational efficiency are reasonable, and yet practically usable.

It should be noted that the utilization of the fuzzy goal programming enabled efficiency to handle a blend of quantitative and so many qualitative variables, which are an attribute of most realistic optimization problems, inherently the situation in case of optimizing the smart workplace design problem.

In the future, improvement of the presented methodology could be achieved through improving the utilization of fuzzy relations and devising a method for ensuring consistency of the expert's judgments.

Author Contributions: All of the authors contributed significantly to the research. The contributions according to the CRediT taxonomy are: Conceptualization, S.A., J.T. and I.V.; methodology, S.A., J.T. and I.V.; software, S.A., J.T. and I.V.; validation, S.A., J.T. and I.V.; formal analysis, S.A., J.T. and I.V.; investigation, S.A., J.T. and I.V.; resources, S.A., J.T. and I.V.; data curation, S.A., J.T. and I.V.; writing—original draft preparation, S.A., J.T. and I.V.; writing—review and editing, S.A., J.T. and I.V.; visualization, S.A., J.T. and I.V.; supervision, S.A., J.T. and I.V.; project administration, S.A., J.T. and I.V. All authors have read and agreed to the published version of the manuscript.

Funding: This work was conducted within the project "Applications of Machine Learning and Data Mining in Optimizing Decision making in Smart Environments" (2019MEZ0010) funded through the IGA Foundation of the Faculty of Economics and Management, Czech University of Life Sciences Prague, Czech Republic.

Data Availability Statement: Not applicable.

Acknowledgments: Authors thank to Faculty of Engineering at Helwan, Helwan University, Faculty of Economics \& Management Czech University of Life Sciences and the IGA Foundation of the Faculty of Economics and Management for their support of this research.

Conflicts of Interest: The authors declare no conflict of interest.

\section{Appendix A. The Smart Enabling Technologies (SETs)}

List of the smart enabling technologies (SETs), their potential application, estimated cost range. 
Table A1. List of the smart enabling technologies (SETs), their potential application, estimated cost range.

\begin{tabular}{|c|c|c|c|c|}
\hline Tech. No. & Technology Concept & $\begin{array}{l}\text { Measure/Senses/ } \\
\text { Support }\end{array}$ & $\begin{array}{l}\text { Application and Deployment } \\
\text { in Smart Hospital }\end{array}$ & $\begin{array}{l}\text { Cost Range } \\
\text { (Min-Max) }\end{array}$ \\
\hline $\mathrm{T}_{1}$ & $\begin{array}{l}\text { Motion sensor (e.g., PIR } \\
\text { motion sensor) }[22,23]\end{array}$ & Motion/direction & $\begin{array}{l}\text { Detecting motions and presence } \\
\text { of patients and staff for the } \\
\text { safety of patient and assets } \\
\text { security as well as energy saving }\end{array}$ & $\$ 7-50$ \\
\hline $\mathrm{T}_{2}$ & $\begin{array}{l}\text { Outdoor positioning } \\
\text { system [40] }\end{array}$ & GPS tracker & $\begin{array}{l}\text { Tracking patients outdoor (e.g., } \\
\text { in the Garden, or in proximity) }\end{array}$ & $\$ 25-200$ \\
\hline $\mathrm{T}_{3}$ & $\begin{array}{l}\text { Indoor Positioning } \\
\text { Proximity sensor (e.g., } \\
\text { RFID Tag/Reader) [22] }\end{array}$ & $\begin{array}{l}\text { Position/presence/ } \\
\text { proximity/distance }\end{array}$ & $\begin{array}{l}\text { Detecting and identifying } \\
\text { people. Usually they work } \\
\text { together with motion sensors. It } \\
\text { can hold information about } \\
\text { object identity and other details. }\end{array}$ & $\$ 25-200$ \\
\hline $\mathrm{T}_{4}$ & $\begin{array}{l}\text { Indoor navigation system } \\
{[41,42]}\end{array}$ & $\begin{array}{l}\text { Bluetooth Low Energy } \\
\text { (BLE) beacon }\end{array}$ & $\begin{array}{c}\text { Guiding patients and visitors to } \\
\text { the target destination in the } \\
\text { hospital building }\end{array}$ & $\$ 20-30$ \\
\hline $\mathrm{T}_{5}$ & $\begin{array}{l}\text { Video camera (e.g., } \\
\text { Monocular/3D stereo } \\
\text { camera) }[43]\end{array}$ & $\begin{array}{l}\text { Real-time videos and } \\
\text { images }\end{array}$ & $\begin{array}{l}\text { Real-time monitoring and } \\
\text { recording of videos and images. }\end{array}$ & $\$ 25-275$ \\
\hline $\mathrm{T}_{6}$ & $\begin{array}{l}\text { Speech recognition } \\
\text { interface, Speech/Voice } \\
\text { recognition engine [44] }\end{array}$ & Senses voice and speech & $\begin{array}{l}\text { Provides for natural, multimodal } \\
\text { interaction and control with } \\
\text { some objects in the like medical } \\
\text { devices, lights, etc. }\end{array}$ & $\$ 2500-3500$ \\
\hline $\mathrm{T}_{7}$ & $\begin{array}{l}\text { Head Mounted Display } \\
\text { (HMD) (e.g., Sony and } \\
\text { Google HMD) [45] }\end{array}$ & Supporting technologies & $\begin{array}{l}\text { Provide virtual reality for } \\
\text { displays and visualization, etc. }\end{array}$ & $\$ 185-250$ \\
\hline $\mathrm{T}_{8}$ & Smartwatch [27] & $\begin{array}{l}\text { GPS, accelerator, } \\
\text { thermometer, etc. }\end{array}$ & $\begin{array}{c}\text { Tracking physiological } \\
\text { parameters, indoor and } \\
\text { positioning, and can act as a fall } \\
\text { detector }\end{array}$ & $\$ 120-350$ \\
\hline $\mathrm{T}_{9}$ & $\begin{array}{c}\text { EMG (Electromyography) } \\
{[22,26]}\end{array}$ & $\begin{array}{l}\text { Detect muscle } \\
\text { malfunctions/injuries }\end{array}$ & $\begin{array}{l}\text { Monitors motor health and } \\
\text { detect movement disorder for } \\
\text { patients and staff. }\end{array}$ & $\begin{array}{l}\text { EMG (Machine): } \\
\$ 6000-\$ 14,500\end{array}$ \\
\hline $\mathrm{T}_{10}$ & $\begin{array}{l}\text { Electrocardiography } \\
\quad(\text { ECG) }[22,25]\end{array}$ & $\begin{array}{l}\text { Detect cardiac } \\
\text { abnormalities }\end{array}$ & $\begin{array}{l}\text { Monitors cardiac parameters for } \\
\text { patient and staff }\end{array}$ & ECG: \$76-240 \\
\hline $\mathrm{T}_{11}$ & $\begin{array}{l}\text { Contact thermometry } \\
\text { (Skin temperature) [22] }\end{array}$ & $\begin{array}{l}\text { Measures body } \\
\text { temperature }\end{array}$ & $\begin{array}{l}\text { Monitors temperature of patients } \\
\text { and hospital staff }\end{array}$ & $\begin{array}{l}\text { Contact thermometry: } \\
\qquad \$ 30-120\end{array}$ \\
\hline $\mathrm{T}_{12}$ & $\begin{array}{l}\text { Activity Tracker } \\
\text { Wearables [46] }\end{array}$ & $\begin{array}{l}\text { Tracking physical } \\
\text { activities }\end{array}$ & $\begin{array}{l}\text { Monitor physiological and } \\
\text { various health parameters like } \\
\text { heartbeat rate, blood pressure, } \\
\text { etc., of the patients and staff. }\end{array}$ & $\$ 30-60$ \\
\hline $\mathrm{T}_{13}$ & $\begin{array}{l}\text { Computer brain interface } \\
\text { (CBI) [29] }\end{array}$ & $\begin{array}{l}\text { Enable using brain } \\
\text { signals for controlling } \\
\text { devices }\end{array}$ & $\begin{array}{l}\text { Enabling patients with severe } \\
\text { disability to communicate and } \\
\text { control computer and devices } \\
\text { using brains signal and } \\
\text { implanted electrodes }\end{array}$ & $\$ 100-5000$ \\
\hline $\mathrm{T}_{14}$ & Eye-tracking system [28] & $\begin{array}{l}\text { Measures eyes } \\
\text { movement }\end{array}$ & $\begin{array}{l}\text { Uses measures of eye } \\
\text { movements to control devices or } \\
\text { monitor behavior. }\end{array}$ & $\$ 1000-17,000$ \\
\hline $\mathrm{T}_{15}$ & Smoke detector [47] & Sense smoke & Detect smoke in hospital rooms. & $\$ 20-65$ \\
\hline $\mathrm{T}_{16}$ & Fall detector [26] & Detect fall or acceleration & $\begin{array}{l}\text { Monitor patent or staff to detect } \\
\text { fall or measure their acceleration }\end{array}$ & $\$ 40-175$ \\
\hline
\end{tabular}


Table A1. Cont.

\begin{tabular}{|c|c|c|c|c|}
\hline Tech. No. & Technology Concept & $\begin{array}{c}\text { Measure/Senses/ } \\
\text { Support } \\
\end{array}$ & $\begin{array}{l}\text { Application and Deployment } \\
\text { in Smart Hospital }\end{array}$ & $\begin{array}{l}\text { Cost Range } \\
\text { (Min-Max) }\end{array}$ \\
\hline $\mathrm{T}_{17}$ & $\begin{array}{l}\text { Bed pressure sensor } \\
\text { (Medical) [24] }\end{array}$ & Patient wakeup sensor & $\begin{array}{l}\text { Monitor patient sleeping and } \\
\text { wakeup to ensure safety. }\end{array}$ & $\$ 50-250$ \\
\hline $\mathrm{T}_{18}$ & $\begin{array}{c}\text { Wireless network router } \\
\text { (e.g., WiFi, ZigBee, } \\
\text { Bluetooth) [48] }\end{array}$ & $\begin{array}{l}\text { Wireless data } \\
\text { communication }\end{array}$ & $\begin{array}{l}\text { Necessary to enable internet } \\
\text { access, data communication, and } \\
\text { indoor/outdoor positioning. }\end{array}$ & $\begin{array}{c}\text { WiFi: } \$ 20-100 \\
\text { ZigBee: } \$ 30-50 \\
\text { Bluetooth: } \$ 200-500\end{array}$ \\
\hline $\mathrm{T}_{19}$ & $\begin{array}{c}\text { Control software (e.g., } \\
\text { Home Gateway, etc.) [49] }\end{array}$ & $\begin{array}{l}\text { Support software control } \\
\text { of sensors and actuators } \\
\text { in the environment. }\end{array}$ & $\begin{array}{l}\text { Connect, control and coordinate } \\
\text { physiological and various health } \\
\text { sensors, actuators with computer } \\
\text { and web. }\end{array}$ & $\$ 200-1500$ \\
\hline
\end{tabular}

\section{Appendix B. Application of PROMETHEE Technique to the Example}

Table A2. Expert's preference rating of the clinic's operational objectives with respect to goals.

\begin{tabular}{cccccccc}
\hline Overall Goal & $\mathbf{O}_{\mathbf{1}}$ & $\mathbf{O}_{\mathbf{2}}$ & $\mathbf{O}_{\mathbf{3}}$ & $\mathbf{O}_{4}$ & $\mathbf{O}_{5}$ & $\mathbf{O}_{\mathbf{6}}$ & $\mathbf{O}_{\mathbf{7}}$ \\
\hline $\mathbf{O G}_{\mathbf{1}}$ & 9 & 8 & 9 & 8 & 7 & 9 & 6 \\
\hline $\mathbf{O G}_{\mathbf{2}}$ & 9 & 9 & 7 & 9 & 9 & 6 & 8 \\
\hline
\end{tabular}

Table A3. Expert's specification of the goals' thresholds and weights.

\begin{tabular}{cccc}
\hline Overall Goal & q Threshold & p Threshold & Weights \\
\hline OG $_{1}$ & 1 & 2 & 0.5 \\
\hline OG $_{2}$ & 1 & 2 & 0.5 \\
\hline
\end{tabular}

Table A4. The result of PROMETHEE performance flows and outranking of the clinic's OOs.

\begin{tabular}{|c|c|c|c|c|c|c|}
\hline $\begin{array}{l}\text { Operational } \\
\text { Objectives }\end{array}$ & $\varphi_{a}^{+}$ & $\varphi_{a}^{-}$ & $\varphi_{a}^{n e t}$ & Rank & $\begin{array}{l}\text { Equivalent } \\
\text { Weight * }\end{array}$ & $\begin{array}{c}\text { Normalized } \\
\text { Weight ** }\end{array}$ \\
\hline $\begin{array}{c}\mathrm{O}_{1:} \text { Speed-up } \\
\text { patient check-in }\end{array}$ & 0.3333 & 0.0000 & 0.3333 & 1 & 100 & 0.21 \\
\hline $\begin{array}{l}\mathrm{O}_{2:} \text { Optimize } \\
\text { patient flow }\end{array}$ & 0.2500 & 0.0000 & 0.2500 & 2 & 91.67 & 0.19 \\
\hline $\begin{array}{l}\mathrm{O}_{3:} \text { Enhance } \\
\text { information }\end{array}$ & 0.1667 & 0.3333 & -0.1667 & 5 & 50 & 0.11 \\
\hline $\begin{array}{c}\mathrm{O}_{4:} \text { Speed-up } \\
\text { diagnosis }\end{array}$ & 0.2500 & 0.0000 & 0.2500 & 3 & 91.67 & 0.19 \\
\hline $\begin{array}{c}\mathrm{O}_{5:} \text { Improve } \\
\text { safety and } \\
\text { security }\end{array}$ & 0.1667 & 0.2500 & -0.0833 & 4 & 58.34 & 0.13 \\
\hline $\begin{array}{l}\mathbf{O}_{6:} \text { Minimize } \\
\text { energy } \\
\text { consumption }\end{array}$ & 0.1667 & 0.4167 & -0.2500 & 6 & 41.67 & 0.09 \\
\hline $\begin{array}{l}\mathbf{O}_{7:} \text { Track people } \\
\text { and assets }\end{array}$ & 0.0833 & 0.4167 & -0.3333 & 7 & 33.34 & 0.07 \\
\hline
\end{tabular}

${ }^{*}\left[\varphi_{a}^{\text {net }} * 100+(100-33.33)\right] ;{ }^{* *}$ Equivalent weight $/ \sum$ Equivalent weight. 


\section{References}

1. Kbar, G.; Aly, S. SMART workplace for Persons with DISABiLitiEs (SMARTDISABLE). In Proceedings of the IEEE International Conference on Multimedia Computing and Systems (ICMCS), Marrakech, Morocco, 14-16 April 2014; pp. $996-1001$.

2. Kbar, G.; Aly, S.; Elsharawy, I.; Bhatia, A.; Alhasan, N.; Enriquez, R. Smart help at the workplace for persons with disabilities (SHW-PWD). Int. J. Comput. Control Quantum Inf. Eng. 2015, 9, 84-90.

3. Aly, S.; Pelikan, M.; Vrana, I. Designing smart manufacturing workplace utilizing fuzzy screening approach. In Proceedings of the 4th International Conference on Systems and Informatics (ICSAI), Hangzhou, China, 11-13 November 2017 ; pp. 616-621.

4. Aly, S.; Pelikan, M.; Vrana, I. A novel methodology for designing smart workplace environments utilizing fuzzy relations. J. Ambient. Intell. Smart Environ. 2018, 10, 169-193. [CrossRef]

5. Tian, S.; Yang, W.; Le Grange, J.M.; Wang, P.; Huang, W.; Ye, Z. Smart healthcare: Making medical care more intelligent. Glob. Heal. J. 2019, 3, 62-65. [CrossRef]

6. Turk, M.; Pipan, M.; Simic, M.; Herakovic, N. A Smart Algorithm for Personalizing the Workstation in the Assembly Process. Appl. Sci. 2020, 10, 8624. [CrossRef]

7. Forcina, A.; Introna, V.; Silvestri, A. Enabling technology for maintenance in a smart factory: A literature review. Procedia Comput. Sci. 2021, 180, 430-435. [CrossRef]

8. Zhao, N.; Seitinger, S.; Richer, R.; Paradiso, J.A. Real-time work environment optimization using multimodal media and body sensor network. Smart Health 2021, 19, 100164. [CrossRef]

9. Turk, M.; Resman, M.; Herakovič, N. The impact of smart technologies: A case study on the efficiency of the manual assembly process. Procedia CIRP 2021, 97, 412-417. [CrossRef]

10. Tewary, S.; Chakraborty, S.; Majumdar, J.; Majumder, R.; Kundu, D.; Ghosh, S.; Das Gupta, S. A novel approach towards designing a wearable Smart Health Monitoring System measuring the vital parameters and emergency situations in real-time and providing the necessary medical care through telemedicine. In Proceedings of the 2016 IEEE Students' Conference on Electrical, Electronics and Computer Science (SCEECS), Bhopal, India, 5-6 March 2016.

11. Khan, T.; Chattopadhyay, M.K. Smart health monitoring system. In Proceedings of the 2017 International Conference on Information, Communication, Instrumentation and Control (ICICIC), Indore, India, 17-19 August 2017.

12. Khayal, I.S.; Farid, A.M. An Architecture for a Cyber-Physical Healthcare Delivery System with Human Agents. In Proceedings of the 2017 IEEE First Summer School on Smart Cities (S3C), Natal, Brazil, 6-11 August 2017.

13. Arefin, S.; Surovi, T.H.; Snigdha, N.N.; Mridha, F.; Adnan, A. Smart health care system for underdeveloped countries. In Proceedings of the 2017 IEEE International Conference on Telecommunications and Photonics (ICTP), Dhaka, Bangladesh, 26-28 December 2017.

14. Bansal, M.; Gandhi, B. IoT \& Big Data in Smart Healthcare (ECG Monitoring). In Proceedings of the 2019 International Conference on Machine Learning, Big Data, Cloud and Parallel Computing (COMITCon), Faridabad, India, 14-16 February 2019.

15. Feng, B.; He, P.; Li, P.; Yao, H.; Ji, Y.; He, J. Developing a smart healthcare framework with an 'Aboriginal lens'. Procedia Comput. Sci. 2019, 162, 347-354. [CrossRef]

16. Almazroa, A.; Alsalman, F.; Alsehaibani, J.; Alkhateeb, N.; AlSugeir, S. Easy Clinic: Smart Sensing Application in Healthcare. In Proceedings of the 2nd International Conference on Computer Applications \& Information Security (ICCAIS), Riyadh, Saudi Arabia, 1-3 May 2019.

17. Kamruzzaman, M.M. Architecture of Smart Health Care System Using Artificial Intelligence. In Proceedings of the 2020 IEEE International Conference on Multimedia \& Expo Workshops (ICMEW), London, UK, 6-10 July 2020.

18. Rajakumari, K.; Madhunisha, M. Intelligent and Convolutional-Neural-Network based Smart Hospital and Patient Scheduling System. In Proceedings of the 2020 International Conference on Computer Communication and Informatics (ICCCI), Coimbatore, India, 22-24 January 2020.

19. Xie, Z.; Ji, X.; Han, J. Design of hospital IoT smart system and nucleoside drugs for treatment of hepatitis and liver cirrhosis. Microprocess. Microsyst. 2021, 81, 103691. [CrossRef]

20. Zhao, Y.; Ge, S.; Feng, Y. Smart IoT data platform in hospital and postoperative analgesic effects of orthopedic patients. Microprocess. Microsyst. 2021, 81, 103653. [CrossRef]

21. Ahmid, M.; Kazar, O.; Benharzallah, S.; Kahloul, L.; Merizig, A. An Intelligent and Secure Health Monitoring System Based on Agent. In Proceedings of the 2020 IEEE International Conference on Informatics, IoT, and Enabling Technologies (ICIoT), Doha, Qatar, 2-5 February 2020.

22. Chan, M.; Estève, D.; Escriba, C.; Campo, E. A review of smart homes-Present state and future challenges. Comput. Methods Programs Biomed. 2008, 91, 55-81. [CrossRef]

23. Bernal Monroy, E.; Polo Rodríguez, A.; Espinilla Estevez, M.; Medina Quero, J. Fuzzy monitoring of in-bed postural changes for the prevention of pressure ulcers using inertial sensors attached to clothing. J. Biomed. Inform. 2020, 107, 103476. [CrossRef] [PubMed]

24. Rashidi, P.; Mihailidis, A. A Survey on Ambient-Assisted Living Tools for Older Adults. IEEE J. Biomed. Health Inform. 2013, 17, 579-590. [CrossRef]

25. Riyadi, M.A.; Iskandar, I.A.; Rizal, A. Development of FPGA-based three-lead electrocardiography. In Proceedings of the 2016 International Seminar on Intelligent Technology and Its Applications (ISITIA), Lombok, Indonesia, 28-30 July 2016 ; pp. 67-72. 
26. Han, H.; Ma, X.; Oyama, K. Towards detecting and predicting fall events in elderly care using bidirectional electromyographic sensor network. In Proceedings of the 15th International Conference on Computer and Information Science (ICIS), Okayama, Japan, 26-29 June 2016.

27. Reeder, B.; David, A. Health at hand: A systematic review of smart watch uses for health and wellness. J. Biomed. Inform. 2016, 63, 269-276. [CrossRef]

28. Bissoli, A.; Lavino-Junior, D.; Sime, M.; Encarnação, L.; Bastos-Filho, T. A Human-Machine Interface Based on Eye Tracking for Controlling and Monitoring a Smart Home Using the Internet of Things. Sensors 2019, 19, 859. [CrossRef] [PubMed]

29. Vourvopoulos, A.; Badia, S.B. i Usability and Cost-effectiveness in Brain-Computer Interaction. In Proceedings of the 7th Augmented Human International Conference 2016, New York, NY, USA, 25-27 February 2016; ACM: New York, NY, USA, 2016; pp. 1-8. [CrossRef]

30. Brans, J.P. L'ingénièrie de la décision: Elaboration d'instruments d'aide à la décision. La méthode PROMETHEE. In L'aide à la décision: Nature, Instruments et Perspectives d'Avenir; Nadeau, R., Landry, M., Eds.; Presses de l'Université Laval: Québec, QC, Canada, 1982; pp. 183-213.

31. Brans, J.P.; Vincke, P. PROMETHEE, a new family of outranking methods in MCDM. Manag. Sci. 1985, 31, 647-656. [CrossRef]

32. Brans, J.P.; Mareschal, B. The PROMCALC and GAIA decision support system for MCDA. Decis. Support Syst. 1994, 12, 297-310. [CrossRef]

33. Mergias, I.; Moustakas, K.; Papadopoulos, A.; Loizidou, M. Multi-criteria decision aid approach for the selection of the best compromise management scheme for ELVs: The case of Cyprus. J. Hazard. Mater. 2007, 147, 706-717. [CrossRef]

34. Zadeh, L.A. Fuzzy sets. Inf. Control 1965, 8, 338-353. [CrossRef]

35. Zimmermann, H.-J. Description and optimization of fuzzy systems. Int. J. Gen. Syst. 1976, 2, 209-215. [CrossRef]

36. Kanakana-Katumba, G.M.; Makinde, O.A. A Goal Programming Model for Production Planning in a Small and Medium Bottled Water Manufacturing Enterprise. In Proceedings of the International Conference on Industrial Engineering and Operations Management, Pretoria, South Africa, 30 October-1 November 2018.

37. Bhargava, A.K.; Singh, S.R.; Bansal, D. Fuzzy Goal Programming Techniques for Production Planning in Industry. Int. J. Comput. Appl. Technol. Res. 2015, 4, 92-96. [CrossRef]

38. Zimmermann, H.-J. Fuzzy programming and linear programming with several objective functions. Fuzzy Sets Syst. 1978, 1, 45-55. [CrossRef]

39. Taha, H. Operations Research: An Introduction, 8th ed.; Pearson: Upper Saddle River, NJ, USA, 2007.

40. He, Z.M.; Peng, L.; Han, H.Y.; Lu, H.; Wang, Z.F.; Zhao, P. Research on Indoor and Outdoor Comprehensive Positioning Technology Based on Multi-Source Information Assistance. Procedia Comput. Sci. 2020, 166, 361-365. [CrossRef]

41. Mohsin, N.; Payandeh, S.; Ho, D.; Gelinas, J.P. Study of Activity Tracking through Bluetooth Low Energy-Based Network. J. Sens. 2019, 2019, 1-21. [CrossRef]

42. AL-Madani, B.; Orujov, F.; Maskeliūnas, R.; Damaševičius, R.; Venčkauskas, A. Fuzzy Logic Type-2 Based Wireless Indoor Localization System for Navigation of Visually Impaired People in Buildings. Sensors 2019, 19, 2114. [CrossRef]

43. Rougier, C.; Meunier, J.; St-Arnaud, A.; Rousseau, J. Monocular 3D Head Tracking to Detect Falls of Elderly People. In Proceedings of the 28th Annual International Conference of the IEEE Engineering in Medicine and Biology Society, EMBS ‘06, New York, NY, USA, 30 August-3 September 2006.

44. Bhavsar, M.; Kosaraju, P.; Anan-thakrishnan, G.; Shet, G.S.; Anand, S. Dynamic Improvements in a Cloud Based Speech Recognition Engine by Incorporating Trending Data. In Proceedings of the 4th IEEE International Conference on Mobile Cloud Computing, Services, and Engineering (MobileCloud), Oxford, UK, 29 March-1 April 2016; pp. 60-66.

45. Azimi, E.; Doswell, J.; Kazanzides, P. Augmented reality goggles with an integrated tracking system for navigation in neurosurgery. In Proceedings of the 2012 IEEE Virtual Reality (VR), Costa Mesa, CA, USA, 4-8 March 2012; pp. 123-124.

46. Shin, G.D. Investigating the impact of daily life context on physical activity in terms of steps information generated by wearable activity tracker. Int. J. Med. Inform. 2020, 141, 104222. [CrossRef]

47. Festag, S. Analysis of the effectiveness of the smoke alarm obligation-Experiences from practice. Fire Saf. J. 2021, 119, 103263. [CrossRef]

48. Gomez, C.; Paradells, J. Wireless home automation networks: A survey of architectures and technologies. IEEE Commun. Mag. 2010, 48, 92-101. [CrossRef]

49. Skubic, M.; Alexander, G.; Popescu, M.; Rantz, M.; Keller, J. A smart home application to eldercare: Current status and lessons learned. Technol. Health Care 2009, 17, 183-201. [CrossRef] [PubMed] 